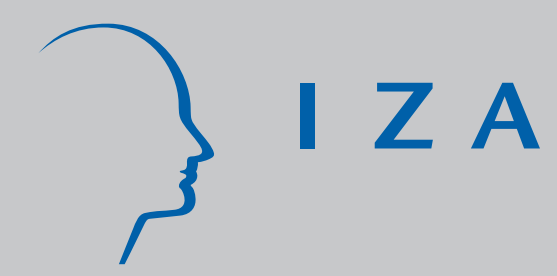

IZA DP No. 406

\title{
Labor Market Flows and Equilibrium Search
} Unemployment

Pietro Garibaldi

Etienne Wasmer

November 2001 


\title{
Labor Market Flows and Equilibrium Search Unemployment
}

\author{
Pietro Garibaldi \\ Bocconi University and CEPR
}

Etienne Wasmer

ECARES, ULB, Université de Metz, CEPR and IZA, Bonn

\author{
Discussion Paper No. 406 \\ November 2001
}

\author{
IZA \\ P.O. Box 7240 \\ D-53072 Bonn \\ Germany \\ Tel.: +49-228-3894-0 \\ Fax: +49-228-3894-210 \\ Email: iza@iza.org
}

This Discussion Paper is issued within the framework of IZA's research area Mobility and Flexibility of Labor. Any opinions expressed here are those of the author(s) and not those of the institute. Research disseminated by IZA may include views on policy, but the institute itself takes no institutional policy positions.

The Institute for the Study of Labor (IZA) in Bonn is a local and virtual international research center and a place of communication between science, politics and business. IZA is an independent, nonprofit limited liability company (Gesellschaft mit beschränkter Haftung) supported by the Deutsche Post AG. The center is associated with the University of Bonn and offers a stimulating research environment through its research networks, research support, and visitors and doctoral programs. IZA engages in (i) original and internationally competitive research in all fields of labor economics, (ii) development of policy concepts, and (iii) dissemination of research results and concepts to the interested public. The current research program deals with (1) mobility and flexibility of labor, (2) internationalization of labor markets, (3) the welfare state and labor markets, (4) labor markets in transition countries, (5) the future of labor, (6) evaluation of labor market policies and projects and (7) general labor economics.

IZA Discussion Papers often represent preliminary work and are circulated to encourage discussion. Citation of such a paper should account for its provisional character. 


\section{ABSTRACT}

\section{Labor Market Flows and Equilibrium Search Unemployment*}

This paper explicitly differentiates between unemployment and inactivity, by defining inactivity as a state in which individuals do not search for jobs when non-employed. Facing changes in the value of inactivity, individuals transit through three labor market states. In steady-state, we hence have a theory of equilibrium unemployment determined by both matching frictions and labor market participation margins. The paper firstly rationalizes and quantitatively accounts for the existence of large flows between employment, unemployment and inactivity. Secondly, it shows that unemployment and aggregate wages rise because some of the employed workers are unattached to the labor force, in the sense that they join the inactive pool when they lose a job. Thirdly, unemployment income has little effects on employment, since it attracts people into the labor force and rises the share of attached workers. Finally, our theory suggests that contrary to two-state models, taxation of market activity increases non-participation, unattachment and adversely affects unemployment.

JEL Classification: J2, J30

Keywords: Unemployment, matching, home production

Etienne Wasmer

ECARES

Université Libre de Bruxelles

CP 114

Avenue Franklin D. Roosevelt 39

1050 Brussels, Belgium

Tel.: +322650 4212

Fax: +322650 4475

Email: ewasmer@ulb.ac.be

\footnotetext{
* We thank M. Burda, P. Cahuc, M. Dewatripont, E. Faraglia, C. Wyplosz, G. Violante, F. Panunzi, and particularly C. Michelacci and C. Pissarides, for helpful comments, as well as seminar participants at ECARES-ULB, Bank of Italy (Ente Einaudi), Humboldt Universitätt, Berlin, Lausanne (DEEP-HEC), Geneva (IUHEI) Séminaire Fourgeaud in Paris, CEMFI (CEPR Workshop on Unemployment, Redistribution and Inequality), LSE, and the CEPR European Summer Symposium in Labour Economics (ESSLE). We are also indebted to Robert Shimer who kindly provided us with the gross US flows data.
} 


\section{Introduction}

In the labor market, individuals face both idiosyncratic and aggregate shocks. This leads them to take important labor market participation and employment decisions. In aggregate, the transitions resulting from these individual decisions generate extremely large flows between labor market states. Labor force surveys are partly able to recover these flows by classifying individuals in the working age population across three labor market states: employment, unemployment, and out of the labor force. Table 1 reports the magnitude of labor market flows across the three labor market states for the US in any given month. It notably shows that there are huge flows of individuals between employment and out of the labor force. Quantitatively, the number of workers who leave the labor market when they lose their job is larger than the number of workers who join the unemployment pool upon job separation. In this paper, we will refer to the latter type of workers as the attached workers, while the former type of workers are the unattached workers. Our view is that these large flows have a lot to tell to both labour and macroeconomists. Indeed, employment and unemployment changes strongly depend on either the exit rate from employment, notably movements to inactivity, or the entry into unemployment (including movements from inactivity). A proper understanding of aggregate labor market flows must therefore necessarily consider the distinction between attached and unattached workers (see notably Blanchard and Diamond, 1992, and Burda and Wyplosz, 1994 for similar concerns). ${ }^{1}$

Table 1: Average Monthly Flows in the US Labor Market. Millions of Workers; February 1994-November 2000

\begin{tabular}{|c|c|c|c|c|c|c|}
\hline & $E U$ & $E N$ & $U E$ & $U N$ & $\overline{N U}$ & $N E$ \\
\hline 15-64 Population & 1.88 & 4.25 & 2.18 & 2.08 & 1.53 & 3.81 \\
\hline 24-54 Population & 1.16 & 2.04 & 1.26 & 1.02 & 0.7 & 1.80 \\
\hline \multicolumn{7}{|c|}{$\begin{array}{l}E \text { is employment, } N \text { is out of the labor force and } U \text { is unemployment; } \\
\text { The first (second) letter refers to the source (destination) population } \\
\text { e.g. } E U \text { is the employment unemployment flow. } \\
\text { Source. Authors' calculation on data provided by Robert Shimer. }\end{array}$} \\
\hline
\end{tabular}

Beyond labour market flows, there is also a prevalent recognition that understanding the nature and the determinants of the frontier between non-participation and unemployment can improve the understanding of the labour market equilibrium stocks. Juhn et al. (1991) and especially Murphy and Topel (1997) argued that the most precise picture of the labor market is obtained considering jointly non-employment and unemployment figures ${ }^{2}$. Further, the relative size of the labor market, as indicated by the employment population rates, varies substantially across OECD countries, and this cross sectional variation is much more linked

\footnotetext{
${ }^{1}$ Related to the theme of our work although with a less macroeconomic focus, Abraham and Shimer (2001) argue that changes in unemployment duration in the US. are a consequence of greater labor market attachment for women. This result as well as the use of three states flow data was obtained earlier for France in Wasmer (1997).

${ }^{2}$ Murphy and Topel (1997) argue also that the unemployment rate itself became less and less informative over time, as witnessed by the declining employment rate of young unskilled men, despite a constant unemployment rate.
} 
to participation than to unemployment. As the regressions in Table 2 suggest, movements in participation statistically account for most (93\%) of the variance of the employmentpopulation ratio, while unemployment differences statistically account for less than half of it (49\%). In other words, investigating the determination of participation levels across countries is an urgent work to undertake, especially if we want to understand why countries are characterized by labor markets of very different sizes.

Table 2: Employment Population Rates Across Countries; 1980-1998

\begin{tabular}{|l|r|l|}
\hline Dep. Variable & $\begin{array}{l}\text { Employment } \\
\text { Population } \\
\text { Rate }\end{array}$ & $\begin{array}{l}\text { Employment } \\
\text { Population } \\
\text { Rate }\end{array}$ \\
\hline Regressor & -1.58 & - \\
Unemployment Rate & $(0.21)$ & - \\
Participation Rate & - & 1.08 \\
& - & $(0.08)$ \\
\hline Num. Observations & 21 & 21 \\
$R^{2}$ & 0.49 & 0.93 \\
Robust & Yes & Yes \\
\hline Standard errors in parenthesis. \\
Source: Authors' calculation on OECD data. \\
\hline
\end{tabular}

Since both flows and stocks of participants and non-participants are interdependent in several obvious ways, it is natural to argue that macroeconomic theories of the labor market should not ignore participation and non-participation decisions. The macroeconomic theory of the labor market that we propose accounts for the statistical classification made in the empirical analysis of the labor market, notably the distinction between unemployment and inactivity and accounts for five of the six possible flows between the three labor market states and investigates their determinants. It helps us to understand the links between the stock of unemployment, the employment rate and the participation decisions. More precisely, we explore the impact of participation margins on equilibrium employment, unemployment, aggregate wages, aggregate job creation and aggregate participation and provide new insights on equilibrium unemployment and on the effects of taxation. Finally, our approach help us to understand the respective role of redistribution to inactivity (housing and family benefits) and unemployment benefits.

Specifically, we model participation to the labor market in a flows-matching macroeconomic model. We start from the convenient Pissarides (1990) and Mortensen-Pissarides (1994) approach, on which we build on. We specify new margins, i.e. arbitrage of workers between activity and inactivity. Our three states representation of the labor market adds two new margins: the quit margin on which workers are indifferent between employment and inactivity; and the entry margin on which workers are indifferent between being unemployed and inactive. This, in turn, creates a distinction between attached and unattached workers: the latter prefer inactivity to unemployment, while the former prefer unemployment to inactivity. For the sake of clarity, and to avoid to enter the debate on the distinction between unemployment and out-of-the-labor force, we define unemployment as a state where workers actively look for a job, and non-participation as a state in which it is optimal for workers 
not to search for a job. ${ }^{3}$

Several new insights emerge from our three states representation of the labor market. We show that equilibrium unemployment depends, for at least four reasons, on turnover along the entry and exit margin of labor supply, and on the flows from employment to inactivity. First, in steady-state the latter flows have to be compensated by inflows of new entrants to the labor market in order to maintain employment, with an endogenous increase in the aggregate amount of frictions. Second, wages are determined by the comparison of market productivity and outside options of workers. The latter do not only depend on unemployment benefits, but also on a broader concept of "value of inactivity" (leisure, home production, social values), which affects equilibrium unemployment and wage determination in a way that standard models cannot capture. Third, proportional taxation on market activities raises unemployment, by altering the shadow value of market activity relatively to non market activity. Fourth, contrary to standard models, we capture Atkinson and Micklewright's (1991) intuition of a positive role of unemployment benefits, namely making participation to the labor market more attractive.

Perhaps surprisingly, most aggregate models of the labor market have ignored the existence of three separate labor market states, and have instead worked with a two states representation of the labor market. Real business cycle models carefully distinguish between employment and non-employment, but fail to recognize unemployment as an independent labor market state (Benhabib et al. 1991). At the other side of the spectrum, aggregate matching models, arguably a useful tool for dealing with labor market issues, carefully model employment and unemployment, with a remarkable understanding of determinants of their stocks and flows. However, most of these models shut down the participation margin, and have nothing to say on the huge flows between employment and inactivity.

There are two streams of related papers: from the microeconomic side, Seater (1977), Burdett-Mortensen (1978), Burdett (1979), Burdett-Kiefer-Mortensen-Neuman (1984), SwaimPodgursky (1994) have successfully investigated the relations between search frictions and labor supply, with a fixed supply of jobs. Our theoretical distinction between inactivity and unemployment, empirically consistent with Flinn and Heckman (1983), is inspired by Burdett and Mortensen (1978). In the macro-search literature, Bowden (1980), Mc Kenna (1987); Pissarides (1990), chap. 6; Sattinger (1995) have introduced a labor demand side and endogenous participation, in a way that brings few new insights as compared to the standard (two states) model of matching. Individuals, whose value of non-market time is heterogenous, decide in a static (though intertemporal) way about their participation to the labor market. It follows that the flows between activity and inactivity are driven by macroeconomic changes (in productivity, in unemployment) and are thus mainly cyclical or conjunctural flows. In contrast, our theory, building on both macroeconomic factors and

\footnotetext{
${ }^{3}$ Table 1 suggested that there are also large direct flows between inactivity and employment. Scholars of the labor market argue that these flows are due to a time aggregation bias, and would disappear if we could observe individuals continuously. To receive a job offer, one needs to have been active (even marginally) in search and accordingly to be classified as unemployed, in line with our theoretical definition of unemployment. This is discussed further in our calibration section.
} 
individual (household) shocks, is able to account for permanent, structural flows between activity and inactivity, even when macro-conditions are unchanged.

The paper is organized as follows: Section 2 introduces concepts and notation and describes the mechanics of our model. Section 3 develops the first building block of the paper, labor supply, the entry quit margins, and then introduces the second building block, firms and wage determination. Section 4 solves for the general equilibrium and equilibrium unemployment. Section 5 establishes the stylized facts for the labor market flows considered here, proceeds to a cautious calibration of the model to match these flows and then run comparative statics for various parameters. Section 6 discusses the links between participation and unemployment, and notably the transition from a two states model (full attachment) to a three states model, and uses these insights to explain why taxation of activity may or may not be neutral in those two cases. Section 7 discusses further some of our simplifying assumptions. Section 8 details future works.

\section{Description of the model}

We think of an economy composed by a continuum of risk neutral individuals, whose aggregate measure is normalized to one for simplicity. Individuals can be in three different states: employed in the market, unemployed and engaged in job search, and out of the labor force. This immediately raises a question: are unemployment and out of the labor force different states? This recurrent issue should in principle be answered by Flinn and Heckman's (1983) empirical paper, where they show that $U$ (unemployment) and $N$ (inactivity) are actually very distinct states. Here, our definition of unemployment clearly makes a difference between the two states, since by definition unemployment is a state where people actively look for a job. Note that this is consistent with the ILO definition of unemployment in labor force surveys. ${ }^{4}$

Individuals out of the labor force are statistically inactive or non-participants. Though, they derive some utility from leisure and from home production. We assume indeed that at inactivity, workers are in reality engaged in full-time home production. Since we want our model to be as general as possible, we choose a specification of the flows of utility in non-participation which is consistent with both home production and consumption of leisure; Becker's (1965) seminal paper indeed showed that consumption of leisure and home production were formally similar actions, combining time and money to maximize utility. Since activities such as children bearing/rearing, strongly affecting participation to the labor market, can be viewed as home production, we refer hereafter to home production, but it has to be kept in mind that this can also be interpreted as leisure consumption or more generally as the relative utility of non-participation. Existing estimates suggests that the household sector is large, whether measured in terms of inputs or outputs. Data from the Michigan Time Use Survey indicate that an average married couple spends 33 percent

\footnotetext{
${ }^{4}$ More work about the distinction between the two states has been done by the Bureau of Labor Statistics. Sorrentino $(1993,1995)$ shows that different definitions of unemployment sometimes yield different unemployment rates, but the ranking of countries is almost always preserved.
} 
of its discretionary time working for paid compensation and 28 percent working at home. Studies that attempt to measure the value of household production indicate that the sector is very large, with estimates in the range of 20-50 percent of measured gross national product (Eisner's, 1988).

Thus, non-participants are assumed to produce a household good with productivity level $\theta$ that is both stochastic and time varying: home productivity is subject to stochastic shocks that hit individuals with instantaneous probability $\lambda$. Upon the realization of a shock, the home productivity level is drawn from a distribution with support over the interval $\left[\theta^{\min }, \theta^{\max }\right]$ and cumulated distribution function $F$.

Individuals are endowed with 1 unit of time, allocated between three competing activities: home production, time devoted to job search and units of work. For simplicity, we assume that time devoted to market activities is an indivisible choice, and we force individuals to be in or out of the labor force. In the former case, however, they can be employed or unemployed, depending on their history. Employed individuals are matched to a firm and produce a constant productivity flow $y$, receive a wage $w$, and are subject to exogenously determined job destruction shocks at rate $\delta$. Further, we assume separability and linearity to ensure that, at the margin, home production can be perfectly substituted to the consumption of market goods or services: cooking vs. restaurant, personal home cleaning vs. cleaning personnel, etc... are example of substitutability.

Utility of individuals depends on the labor market state, and we let $u^{i}(\theta)$ be the indirect utility function in each of the states $i \in\{w, u, n\}$, corresponding, respectively to employment, unemployment and out of the labor force. To simplify, we further assume that unemployment income is fixed, independent of labor market history and equal to $b$. Under these set of assumptions, the utility flows in the three possible states write:

$$
\begin{aligned}
& u^{w}(\theta)=w(\theta) \text { if employed, } \\
& u^{u}(\theta)=b, \text { if unemployed, } \\
& u^{n}(\theta)=\theta, \text { if out of the labor force, }
\end{aligned}
$$

where the expression $w(\theta)$ explicitly allows for the possibility that wages depend on $\theta$. This will be explored in next Section, where in addition it is shown that $\partial w / \partial \theta$ is a constant of $\theta .^{5}$

While home production is an individual activity, market activity is obtained with a joint process combining an individual worker and a single firm. For simplicity, we assume that each firm is composed of a single job. Firms come to the market by posting vacancies, whose aggregate measure is indicated with $v$, while $u$ indicates the aggregate number of unemployed workers. The matching process brings together individual vacancies and unemployed workers, and is described by an aggregate matching function $m(v, u)$, where $m$, which records the aggregate number of matches formed in the market, is assumed to be increasing in both arguments, differentiable with negative second derivatives, and with constant returns to scale. Thus, hires only come from the pool of the unemployed, consistent with the previous discussion in introduction. The rate at which vacancies are filled is $\chi=\frac{m(v, u)}{v}=\chi(\psi)$, with

\footnotetext{
${ }^{5}$ The indivisibility of labor market participation that is implicit from $u^{u}$ is discussed in Section 7.2.
} 
$\chi^{\prime}<0 . \quad \psi$ is simply the ratio of vacancy to unemployed, often labeled market tightness. Similarly, the rate at which unemployed workers find a job is $p(\psi)=\psi \chi(\psi)$ with $p^{\prime}>0$. Thus, there is a one to one correspondence between $p$ and $\psi$.

Our modelling perspective features home productivity shocks that affect individuals across labor market states. In the aftermath of a home productivity shock, individuals face two endogenous decisions. When an individual is out of the labor force and engaged exclusively in home production, she will have to decide whether, in light of the new home productivity level, she is better off into the labor force as an unemployed worker; further, when an individual is employed and matched to a firm, she will have to decide whether she should quit her job and spend her time in home production. We will show that both decisions are monotonic in the home productivity level $\theta$, satisfy the reservation property, and are thus fully described by two endogenous cut-off levels. In the rest of the paper, we shall indicate with $\theta^{\nu}$ the entry margin, or the home productivity level that makes an individual indifferent between being unemployed or being out of the labor force. Similarly, $\theta^{q}$ shall indicate the home productivity level that makes an individual indifferent between having a job or producing individually. In equilibrium $\theta^{q}$ is larger than $\theta^{\nu}$, so that workers with very high home productivity levels will always be out of the labor force, while workers with home productivity level below $\theta^{\nu}$ will always be in the labor force. In light of the interpretation of $\theta$ previously discussed, individuals with high home productivity are also individuals with high preference for leisure. Workers with home productivity level between the two cut-off values are in the labor force only when they have a job. Thus, our model features two types of employees: attached and unattached workers. 'Attached workers' refers to the employees who join the unemployment pool upon realization of the exogenous destruction shock, while 'unattached workers' refers to the employees that engage their time entirely in home production upon the realization of an adverse shock. Since the share of unattached workers is increasing with the distance between $\theta^{q}$ and $\theta^{\nu}$, the proportion of unattached worker is endogenously determined. Figure 1 summarizes the properties of the distribution in a single chart.

To determine wages and the job finding probability $p$, we follow the traditional matching literature, and we assume that firms post vacancies until full exhaustion of rents. This, in turn, implies that in equilibrium the expected cost of vacancy posting is equal to the value of the average job. Since only the unemployed workers look for a job, firms do not consider workers out of the labor force in their vacancy posting decisions. Wages are the outcome of a bilateral bargaining process, and are set so as to continuously split the surplus from the job. At each instant, the worker gets a fraction $\beta$ of the total surplus. Since separations are jointly efficient, the quit margin $\theta^{q}$ implies zero surplus at the level of the match, and thus there is agreement over the endogenous separation decision. The equilibrium of the model is thus described by the three endogenous variables $\theta^{q}, \theta^{\nu}$ and $p$, or equivalently, by $\left(\theta^{q}, \theta^{\nu}, \psi\right)$ which are consistent with rent sharing and vacancy posting on the part of firms. The next Section starts the formal derivation of the model, while we postpone to Section 7 the discussion of conceptual issues linked to our modelling perspective. 


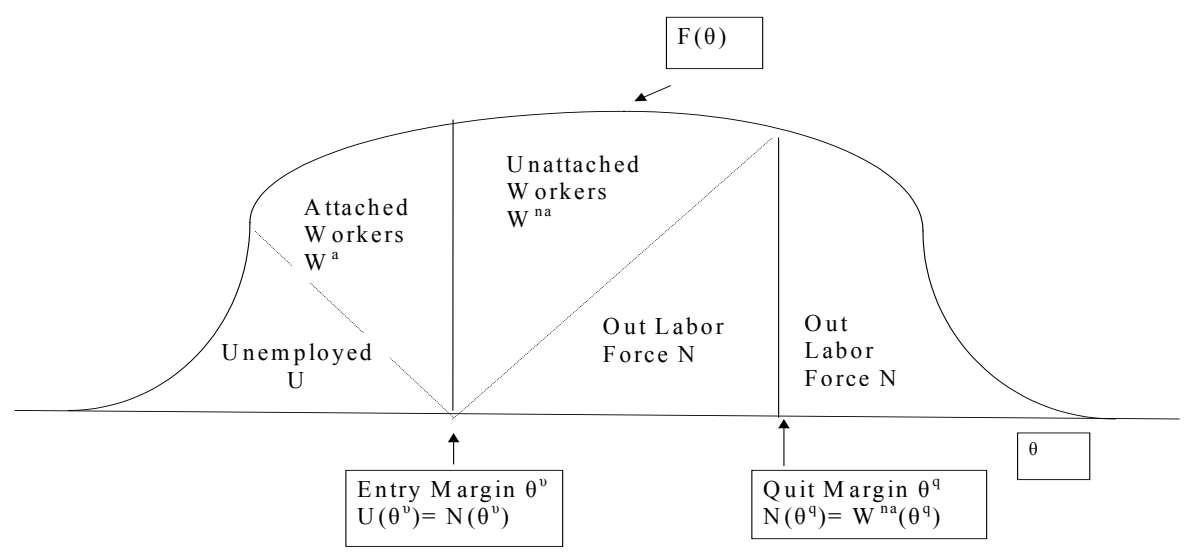

Figure 1: Distribution of Home Productivity Shocks

\section{The model}

We here introduce the first building block of the paper, i.e. workers' decisions regarding their labor market status by taking as given the aggregate market conditions $p(\psi)$, and the wage rate. Then, we introduce labor demand, the second block of the paper. In the next Section, we derive the existence and uniqueness conditions.

\subsection{Intertemporal value functions}

At a steady-state, the employed individual has a present discounted value of utility $W$ which writes:

$$
\begin{aligned}
r W(\theta) & =w(\theta)+\delta\{\operatorname{Max}[U(\theta), N(\theta)]-W(\theta)\}+ \\
\lambda & \int_{\theta^{\min }}^{\theta^{\max }}\left\{\operatorname{Max}\left[W\left(\theta^{\prime}\right), U\left(\theta^{\prime}\right), N\left(\theta^{\prime}\right)\right]-W(\theta)\right\} d F\left(\theta^{\prime}\right),
\end{aligned}
$$

where $\delta$ is the job destruction rate, $U(\theta)$ is the value of unemployment, and $N(\theta)$ is the value of devoting all one's time to home production: workers, when hit by a home productivity shock (with intensity $\lambda$ ), decide whether or not to quit their job.

Hereafter, we shall assume that, for every $\theta$ such that $W(\theta)>N(\theta)$, then $W(\theta)>U(\theta)$ (the unemployed workers never reject a job offer at the anticipated equilibrium wage, itself determined later on through bargaining). This corresponds to a restriction on parameters denoted by $\mathcal{R}$, which ensures that the market is viable and is simply, as it will be shown ex-post, $y>b$. It follows that the value of unemployment writes:

$$
\begin{aligned}
r U(\theta) & =b+p[W(\theta)-U(\theta)] \\
& +\lambda \int_{\theta^{\min }}^{\theta^{\max }}\left\{\operatorname{Max}\left[U\left(\theta^{\prime}\right), N\left(\theta^{\prime}\right)\right]-U(\theta)\right\} d F\left(\theta^{\prime}\right),
\end{aligned}
$$


where the last part of the expression reflects the arbitrage between leaving search activities or continuing them.

The value of home production writes

$$
r N(\theta)=\theta+\lambda \int_{\theta^{\min }}^{\theta^{\max }}\left\{\operatorname{Max}\left[U\left(\theta^{\prime}\right), N\left(\theta^{\prime}\right)\right]-N(\theta)\right\} d F\left(\theta^{\prime}\right),
$$

and similarly, inactive workers, hit by a shock, decide whether to participate to the labor market or remain inactive.

\subsection{Reservation values of $\theta$ : the entry and quit margins}

In this subsection, we assume that a reservation strategy exists and determines two threshold values $\theta^{q}$ and $\theta^{\nu}$ above which, respectively, workers quit because they prefer inactivity to employment, and cancel job search because they prefer inactivity. ${ }^{6}$ In addition, we assume that the parameters are such that $\theta^{q}>\theta^{\nu}$ : this corresponds to $\mathcal{R}$, the same restriction on parameters for having $W>U$, again as shown ex-post.

More formally, $\theta^{q}$ is the productivity of the marginal worker quitting the firm, while $\theta^{\nu}$ is the productivity of the marginal inactive worker entering the labor market. The existence of these two reservation values $\theta^{q}>\theta^{\nu}$ partitions the support of $F$ in three intervals which are characterized by the following relationships: $W(\theta)>U(\theta) \geq N(\theta)$ for $\theta^{\min } \leq \theta \leq \theta^{\nu}$; $W(\theta) \geq N(\theta)>U(\theta)$ for $\theta^{\nu}<\theta \leq \theta^{q}$ and $N(\theta)>W(\theta)>U(\theta)$ for $\theta>\theta^{q}$. Further, the entry margin implies that $N\left(\theta^{\nu}\right)=U\left(\theta^{\nu}\right)$, while the quit margin implies that $N\left(\theta^{q}\right)=W\left(\theta^{q}\right)$. By virtue of these relationships, we say that an individual is respectively:

- out of the labor force if $\theta>\theta^{q}$,

- unattached to the labor force if $\theta^{\nu}<\theta \leq \theta^{q}$ (i.e. possibly employed, but never unemployed),

- attached to the labor force if $\theta^{\min } \leq \theta \leq \theta^{\nu}$.

The goal here is to derive the equations defining $\theta^{\nu}$ and $\theta^{q}$. The inequalities above allow us to substitute for the max signs in the Bellman equations, so that we can solve for the respective value functions. Those equations (21)-(27) are placed in Appendix 9.1 for simplicity of exposition. We also define a useful quantity appearing several times, $\overline{S_{w}}$, defined as the steady-state total surplus of all employed workers or a share of the average surplus for employed workers:

$$
\overline{S_{w}}=\int_{\theta^{\min }}^{\theta^{q}}\left\{W\left(\theta^{\prime}\right)-\operatorname{Max}\left[U\left(\theta^{\prime}\right), N\left(\theta^{\prime}\right)\right]\right\} d F\left(\theta^{\prime}\right) \geq 0 .
$$

\footnotetext{
${ }^{6}$ To prove the existence of these margins, what is needed is the monotonicity of the value function in $\theta$, which depends on the partial derivative of wages with respect to $\theta$, as can be seen from equation (1). We postpone this proof to subsection 3.5.
} 
We can now determine the entry and the quit margins. Replacing the utility flows by their values, using $W\left(\theta^{q}\right)=N\left(\theta^{q}\right)$ one gets the quit margin

$$
\lambda \overline{S_{w}}=\theta^{q}-w\left(\theta^{q}\right)
$$

which simply states that for being indifferent between quitting and remaining employed, the utility flows differential between the states must be equal to the forgone value of seeing a transition to a lower $\theta$ (which makes the employed worker getting a higher surplus).

Noting that $W\left(\theta^{\nu}\right)-U\left(\theta^{\nu}\right)=W\left(\theta^{\nu}\right)-N\left(\theta^{\nu}\right)$ and with equations (21)-(27), one finds the entry margin, defined by:

$$
\theta^{\nu}-b=p\left[W\left(\theta^{\nu}\right)-U\left(\theta^{\nu}\right)\right]
$$

This states that for being indifferent between unemployment and not in the labor force, the utility flows differential between the states must equal the expected gain from searching for a job. Next, we are going to introduce the demand side of the model, by modeling firms' behavior and deriving wages.

\subsection{Firms}

If the asset value of a vacancy is denoted by $V_{V}$ then the value of a job $J(\theta)$ when the worker has home-productivity $\theta$ writes

$$
r J(\theta)=y-w(\theta)+(q+\delta)\left(V_{V}-J(\theta)\right)+\lambda \int_{\theta^{\min }}^{\theta^{q}}\left[J\left(\theta^{\prime}\right)-J(\theta)\right] d F\left(\theta^{\prime}\right),
$$

where $q=\lambda\left(1-F\left(\theta^{q}\right)\right)$ is the quit rate. The right hand side of the equation features the dividend equal to $y-w(\theta)$, the operational profits from the job. Further, the firm may lose the worker at rate $q$, and is left with the value of a vacancy $V_{V}$. Conversely, with the complementary probability (conditional on a change in $\theta$ ), the firm faces a worker with a new $\theta$, but there is no job separation. Finally the match is also subject to destruction shock at rate $\delta$.

Two remarks are in order. First, from the firm's perspective, the quit rate of all workers is the same, given the Poisson process assumption. In that, our model is a macroeconomic model where firms cannot infer from agents types their separation probability. Second, for some workers (but not all) $w$ will depend on $\theta$ even though $\theta$ does not affect the production of the firm. This arises here because wage bargaining involves the outside option of a worker, which is $\operatorname{Max}[U(\theta), N(\theta)]$.

\subsection{Job creation margin}

Denoting by $c$ the flow search cost for firms, the value of a vacancy is

$$
r V_{V}=-c+\chi(\psi)\left[J^{e}-V_{V}\right]
$$


where

$$
J^{e}=\frac{\int_{\theta^{\min }}^{\theta^{\nu}} J\left(\theta^{\prime}\right) d F\left(\theta^{\prime}\right)}{F\left(\theta^{\nu}\right)},
$$

is the expected value of a match for the firm, conditional on the fact that the worker is actually looking for a job, i.e. has a $\theta$ below $\theta^{\nu}$. Indeed, the attached workers are the only one looking for a job.

The third margin is the job creation margin, stating that firms will enter the market up to a point at which all market opportunities are exhausted: free entry in the job market implies full exhaustion of rents. Thus, substituting $V_{V}=0$ in equation (8), the job creation margin is the solution to

$$
c / \chi(\psi)=J^{e}
$$

which states that the expected search costs are equal to the expected value of a job for the firm.

\subsection{Wage bargaining}

To complete the determination of the model we need to specify a wage rule, which we assume to be the standard division of the surplus. In what follows, we denote by $\mathcal{S}(\theta)$ the total surplus associated with a specific match firm/worker, where the worker has homeproductivity $\theta$. Formally, $\mathcal{S}(\theta)$ reads $\mathcal{S}(\theta)=J(\theta)+W(\theta)-\operatorname{Max}[N(\theta), U(\theta)]$. By substituting for the relevant value functions in the definition of the surplus $\mathcal{S}(\theta)$, one immediately notices that the surplus of the unattached workers (for $\theta \in\left[\theta^{\nu}, \theta^{q}\right]$ ) depends on the specific value of $\theta$. However, this is not the case for the attached workers (for $\theta \in\left[\theta^{\min }, \theta^{\nu}\right]$ ), since their outside income is simply $b$, independently of the specific value of $\theta$. This important property (due to the assumption that unemployed workers do not contribute to home-production, see Section 7.2 for a discussion) greatly simplifies the analysis, and allows to obtain the following results for the attached workers $\left(\theta<\theta^{\nu}\right)$ :

- their wage is independent of $\theta$,

- their value functions $W$ and $U$ do not depend on $\theta$,

- the expected surplus of a firm that recruits a worker (necessarily an attached one) is independent of $\theta$.

The surplus $\mathcal{S}(\theta)$ is shared according to a generalized Nash-bargaining with shares $\beta$ to the worker, and $1-\beta$ to the firm. The wage rule satisfies

$$
W(\theta)-\operatorname{Max}(U(\theta), N(\theta))=\beta \mathcal{S}(\theta) .
$$


We thus will have two profiles for wages, one for the attached workers, one for the unattached workers. Moreover, the two wages read (see Appendix 9.3):

$$
\begin{aligned}
w_{A} & =(1-\beta) b+\beta(y+\psi c) \quad \forall \theta \leq \theta^{\nu}, \\
w_{N A}(\theta) & =(1-\beta) \theta+\beta y \quad \forall \theta \geq \theta^{\nu} .
\end{aligned}
$$

Four important remarks are in order. First, wages of the unattached workers do not depend on the job finding probability. Second, unattached wages are larger than attached wages. This is easy to establish in remarking that

$$
w_{N A}(\theta)-w_{A}=\left(\theta-\theta^{\nu}\right)(1-\beta)
$$

(see Appendix 9.3). This arises from the fact that workers have the same market productivity but the unattached workers have a better outside option. ${ }^{7}$ Note that it immediately follows that wages at the entry margin are continuous, $w_{N A}\left(\theta^{\nu}\right)=w_{A}$. Third, our model is consistent with an upward sloping wage tenure profile, since the worker starts the relationship as an attached worker, and, on average, finishes his or her relationship as an unattached worker. And forth, given $J\left(\theta^{q}\right)=0$, one has that $w\left(\theta^{q}\right)=y+\frac{1-\beta}{\beta} \lambda \overline{S_{w}}$ : the wage of the marginal worker is above the marginal product, which is a case of labor hoarding. Firms wish to retain the worker with the hope that she will become a (more) attached worker in the future.

Finally, using the wage equations, one can now very easily show that the value functions $W, U$ and $N$ are either constant or monotonic in $\theta$, and thus that the reservation properties in $\theta$ assumed in the beginning of 3.2 are valid.

\section{General equilibrium}

\subsection{Definition}

Denote by $u$ the unemployment rate, i.e. the ratio of the number of unemployed to the active workers; and by $n$ the non-participation rate, i.e. the ratio of the number of inactive workers to the total population (normalized to 1 ). Given that there is a one-to-one correspondence between $p$ and $\psi$, then:

Definition: A market equilibrium is a n-uple $\left(\theta^{\nu}, \theta^{q}, \psi, u, n_{i}\right)$ and two wage rules (one for the attached, one for the unattached workers) satisfying:

- the entry margin for workers,

\footnotetext{
${ }^{7}$ This may however be difficult to reconcile with existing empirical evidence if unattached workers represent women and youngsters, individual who enjoy lower wages in the labor market. However, if markets are segmented, workers with higher transition rates to inactivity, even though they have the same market productivity as other workers, will face a lows labor market tighness. This will reduce the average wage of the group with high unattachment in general equilibrium. Further, in reality, there may be some negative correlation between home and market productivity. Note also all wage differentials across workers in the same segment of the labour market disappear in Section 7.1 when we model asymmetric information on the values of $\theta s$.
} 
- the quit margin for workers,

- the job creation margin for firms,

- the steady-state condition for unemployment flows,

- the steady-state condition for inactivity flows.

This Section aims at showing the existence (and uniqueness) of such an equilibrium. The derivation of the general equilibrium can be decomposed in two parts. The first part involves three equations solving for three endogenous margins: $\theta^{q}, \theta^{\nu}, \psi$. The next part solves for the steady-state values of the flows given the stocks. The three equations of the first part are the following:

$$
\begin{gathered}
\frac{c}{\chi(\psi)}=\frac{(1-\beta)\left(\theta^{q}-\theta^{\nu}\right)}{r+\lambda+\delta}, \\
\theta^{\nu}-b=\frac{\beta c \psi}{1-\beta}, \\
\theta^{q}-y=\frac{\lambda}{r+\lambda+\delta} \int_{\theta^{\nu}}^{\theta^{q}} F(z) d z .
\end{gathered}
$$

The first one, equation (JC), is obtained after an integration by part from the free-entry condition on the parts of firms using $\frac{c}{\chi(\psi)}=J^{A}=J\left(\theta^{\nu}\right)$, by continuity. It simply says that the surplus from a job is equal to the expected search costs. To obtain the second equation, one uses $W-U=\beta /(1-\beta) J$ and equation (9) in equation (6). One obtains the intermediate equation

$$
\theta^{\nu}-b=p(\psi) \frac{\beta\left(\theta^{q}-\theta^{\nu}\right)}{r+\lambda+\delta}
$$

which states that the expected gain of a job is equal to the forgone value of home production. Then, substituting from (JC) into (13) one finally gets a simpler version for the entry margin, equation (Entry). This equation shows that the entry margin $\theta^{\nu}$ is increasing (in partial equilibrium) in $b, \psi$ and $\beta$, the workers' share of the surplus. Finally, recalling the quit margin in equation (5), we obtain the third equation of the model, equation (Quit).

Since (Entry) is a linear relation between $\theta^{\nu}$ and $\psi$, one can easily replace $\theta^{\nu}$ into equation (JC) and equation (Quit). Doing so, one obtains two relations between $\psi$ and $\theta^{q}$ that have opposite slopes. One thus can express the equilibrium in the space $\left[\psi, \theta^{q}\right]$. In what follows and notably in Figure 2, we label the modified first equation the job creation curve, and it is positively sloped. The modified third equation is downward sloping, and is labelled quit margin. Proofs of the slopes are placed in the Appendix 9.4. The intercept of the $\mathrm{JC}$ curve is $b$ and the intercept of the quit margin curve, denoted by $l$ is defined by $l=$ $y+\frac{\lambda}{r+\lambda+\delta} \int_{b}^{l} d F(\theta)>y$. Thus, a sufficient condition for existence and uniqueness is $y>b$. 


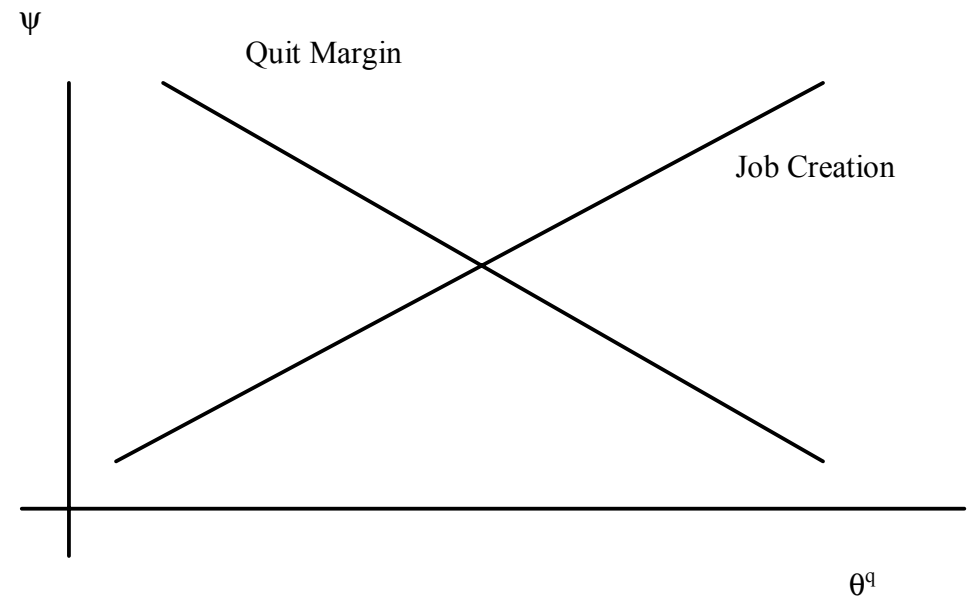

Figure 2: General Equilibrium

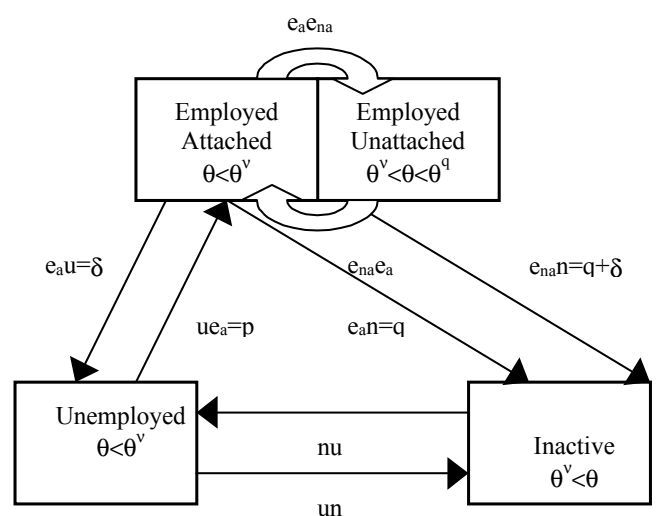

Figure 3: Endogenous Flows between the Different States (Attached Employment; Unattached Employment; Unemployment; Inactivity) 


\subsection{Steady-state unemployment}

In this subsection, we calculate the equilibrium stock of workers in different states. Note first that employed workers facing a shock $\delta$ enter inactivity only if $\theta>\theta^{\nu}$ and search for a new job if $\theta \leq \theta^{\nu}$. All the flows in the model are represented in Figure 3. Note that all transition rates are endogenous, except $e_{a} u=\delta$ which is exogenous, but affects a number of workers that is endogenous. With the steady-state assumption, one obtains (the proof is in Appendix 9.5)

$$
u^{*}=\frac{\delta+q}{p+\delta+q}
$$

with $q=\lambda\left[1-F\left(\theta^{q}\right)\right]$. The steady-state stocks of the other states are too complicated for being reported here, but can be calculated (see a sketch of the calculation in Appendix 9.5).

Equilibrium unemployment deserves four remarks. First, there is a whole new set of parameters determining equilibrium unemployment, through $q$, which are linked to inactivity and household shocks. Those parameters are absent from the classical two states analysis of the labor market. Second, the effect of the quit rate is in steady-state exactly the same as an increase in the job destruction rate: it increases the inflows into unemployment, because the number of people leaving a job for inactivity will be matched by an equivalent number of workers entering activity through unemployment. Thus, the transitions from and to inactivity raise the frictional nature of unemployment. Third, as we have seen in the previous Section, there is also an indirect effect of en: the quit rate is anticipated by firms along the job creation margin, through a reduction in vacancy posting. There is thus an adverse effect on $p$ and thus on unemployment. Finally, there is also the wage effect of unattachment, which reduces further job creation of the labor market (and thus raises $u^{*}$ ).

\section{Calibration and applications}

\subsection{The stylized facts}

Let us first start with a description of the facts we want to illustrate here. We base our calibration on the US flows reported in the introduction. Following Abraham and Shimer (2001), we use the gross monthly flows of workers between the three states E, U and N, applying the Abowd and Zellner (1985) correction for misreported labor market status. In assuming that the errors have not increased over time and as in Abraham and Shimer, that they are in the 1990's independent of gender, we apply the correction displayed in Abowd and Zellner (pp. Table 5, Classification and Margin Error to Unadjusted). We only consider the post-February 1994 period (after the CPS survey redesign) for two groups of workers: the 15-64 population (hereafter referred to as 'total') and the 25-54 population ('prime-age'). When the flows are deflated by the origin population, they are called transition rates. When they are deflated by the total (or prime-age) population, they are called 'flow rates'. We deseasonalized these flows using the X12 Census program available in EViews and computed an average for the period 1994:2 to 2000:11. Tables 3 and 4 indicate the sample averages for the different flows and stocks. 
Table 3: Average Monthly Flows in the US Labor Market. 15-64 Population

\begin{tabular}{|l|c|c|c|c|c|c|}
\hline TOTAL & $e u$ & $e n$ & $u e$ & $u n$ & $n u$ & $n e$ \\
\hline Transitions & 1.550 & 3.459 & 34.37 & 32.86 & 4.055 & 10.11 \\
Flow Rates & 1.140 & 2.549 & 1.306 & 1.255 & 0.916 & 2.228 \\
\hline Stocks & $E / P$ & $U / P$ & $N / P$ & $U / L$ & & \\
& 73.60 & 3.835 & 22.56 & 4.495 & & \\
\hline & $E$ is employment, $N$ is out of the labor force and $U$ is unemployment; \\
The first (second) letter refer to the source (destination) population \\
e.g. $e u$ is the employment unemployment flow. \\
Averages 1994:2 2000:11. Abowd Zellner correction, seasonally adjusted by X11. \\
Source: Gross CPS data provided by Robert Shimer and Authors' calculation. \\
\hline
\end{tabular}

Table 4: Average Monthly Flows in the US Labor Market. 25-54 Population

\begin{tabular}{|l|r|r|r|r|r|c|}
\hline PRIME AGE & $e u$ & $e n$ & $u e$ & $u n$ & $n u$ & $n e$ \\
\hline Transitions & 1.271 & 2.223 & 34.33 & 27.84 & 3.908 & 10.06 \\
Flow Rates & 1.029 & 1.800 & 1.105 & 0.901 & 0.618 & 1.586 \\
\hline Stocks & $E / P$ & $U / P$ & $N / P$ & $U / L$ & & \\
\hline & 80.97 & 3.253 & 15.77 & 3.865 & & \\
\hline \\
The first (second) letter refer to the source (destination) population \\
e.g. eu is the employment unemployment flow. \\
Averages 1994:2 2000:11. Abowd Zellner correction, seasonally adjusted by X11. \\
Source: Gross CPS data provided by Robert Shimer and Authors' calculation. \\
\hline
\end{tabular}

It is remarkable to observe that, even when taking out the extreme of the age distribution, as we do in considering the sample 25-54, one still have large flows from and to inactivity. It is notably the case that exits from employment to unemployment are less frequent than exits from employment to inactivity. All other flows have conventional values. In that period of high tension of the US labor market, the exit rates from unemployment is very high, above $30 \%$. Finally, there are also important direct flows from inactivity to employment, perhaps due to non-corrected misclassification. To make these flows coherent with our theoretical specification, we argue that any person having a job had to make a minimal effort (going to an interview or negotiating the wage or working conditions). In that sense, this person should be classified as job seeker at least five minutes, which obviously surveys cannot detect. This well known phenomenon is a time aggregation bias. Indeed, the existence of ne flows in the CPS survey (as in all other labor force surveys) is a misclassification with respect to our theoretical model, and ne flows should instead add-up to both $n u$ and $u e$ flows.

\subsection{Calibration}

We calibrate the model on the basis of the flow rate, knowing that the stocks are determined in steady-state from these flows. As it is obvious from Tables 3 and 4, there are six flows to consider, while our model can account only for five of them. So, consistent with the model and the discussion above on the infra-month transitions, our calibration will be based on the modified rates: $\tilde{n} \tilde{u}=n u+n e$ and $\tilde{u} \tilde{e}=u e+n e$.

Table 5 reports the calibration exercise for the $15-64$ population. The spirit of the calibra- 
tion exercise was to choose parameter values so as to obtain a model economy that resembled the US labor market in the second half of the nineties. Namely, we calibrated our model economy to have an unemployment rate of 4.5 percent, a participation rate of 76 percent, and a market tightness of 1 , which is a reference value for most of the matching literature. Further, we also calibrated the eu flow rate, which Table 5 shows to be 1.14 percent. In particular, we search the parameter space for values of $y, b, \delta, c, x_{0}{ }^{8}$, with the aim of getting as close as possible to the unemployment rate, the participation rate, market tightness and the $e u$ flow. This calibration exercise leaves us with the following free parameters: $\beta, \eta$, $r, \lambda$ as well as the distribution of productivity shocks. We set the pure monthly discount rates $r$ to $0.005, \beta$ and $\eta$ so that they satisfy the Hosios with a standard reference value of $\beta=\eta=0.5$. The distribution of home productivity was exponential $\left(f(\theta)=B e^{-B \theta}\right)$ with parameter $B=1$, while the arrival rate of the idiosyncratic shock $\lambda$ was exogenously set to 0.14 .

The results of the calibration exercise are reported in the lower part of Table 5. Household production is approximately one fourth of market production $(G N P)$, a statistic which appears to be in line with existing estimates on the size of the informal sector. Table 5 shows that the model economy we constructed not only mimics the calibration statistics, but it seems also capable of matching the relative ranking of all the labor market flows, even though the actual degree of resemblance of the various statistics varies across flows. In particular, our model economy displays larger en and ue flows than those experienced by the US economy, and lower un and $n u$ flows. We believe that the main difference between our statistics and the US statistics are likely due to two specific assumptions of our model: the absence of the discouraged worker effect and the homogeneity of labor force types. In reality, it is well documented that unemployment is a state dependent phenomenon, and workers experiencing long spell of unemployment end up out of the labor force. Accounting for these phenomena would certainly reduce the model generated ue flow, and would simultaneously improve the match of the un flow. The too large en flow calibrated by our model suggests that in reality the share of unattached worker is probably less than the estimated one. A further way to improve the calibration exercise would be to solve the model with two types of workers: one type always attached to the labor force and another type that behaves in a way consistent with the proposed model. Even though these extensions are technically doable, we believe that our model is a very good pass for rationalizing the large US labor market flows. 
Table 5: Calibration to the US Labor Market

\begin{tabular}{|c|c|c|c|}
\hline Parameters & Notation & Value & US Economy \\
\hline Matching Elasticity & $\eta$ & 0.50 & \\
\hline Matching Function Constant & $x_{o}$ & 1.05 & \\
\hline Unemployed Income & $b$ & 1.29 & \\
\hline Discount Rate & $r$ & 0.005 & \\
\hline Idiosyncratic Shock Rate & $\lambda$ & 0.14 & \\
\hline Separation Rate & $\delta$ & 0.02 & \\
\hline Workers' Surplus Share & $\beta$ & 0.50 & \\
\hline Productivity & $y$ & 2.61 & \\
\hline Minimum Home Production $^{a}$ & $\theta^{m \imath n}$ & 0.50 & \\
\hline Search Costs & $c$ & 1.18 & \\
\hline \multicolumn{4}{|l|}{ Equilibrium Values } \\
\hline Entry Margin & $\begin{array}{c}\theta^{\nu} \\
F\left(\theta^{\nu}\right)\end{array}$ & $\begin{array}{l}2.47 \\
0.71\end{array}$ & \\
\hline Quit Margin & $\begin{array}{c}\theta^{q} \\
F\left(\theta^{q}\right)\end{array}$ & $\begin{array}{l}2.84 \\
0.76\end{array}$ & \\
\hline Market Tightness & $\phi$ & 1.00 & \\
\hline \multicolumn{4}{|l|}{ Calibrated Statistics } \\
\hline Unemployment Rate & $u$ & 4.60 & 4.49 \\
\hline Non Participation Rate & $n$ & 26.00 & 26.40 \\
\hline$e u$ flow rate & $e u$ & 1.14 & 1.14 \\
\hline \multicolumn{4}{|l|}{ Implied statistics } \\
\hline share household gdp & & 0.26 & 0.33 \\
\hline en flow rate & en & 2.44 & 2.54 \\
\hline$\tilde{u} \tilde{e}$ flow rate & $\tilde{u} \tilde{e}$ & 4.84 & $3.5=1.3+2.2$ \\
\hline un flow rate & un & 0.19 & 1.2 \\
\hline$\tilde{n} \tilde{u}$ flow rate & $\tilde{n} \tilde{u}$ & 1.06 & $3.2=0.9+2.2$ \\
\hline Attached Employed & $E_{a}$ & 67.55 & \\
\hline Non-Attached Employed & $E_{n a}$ & 3.05 & \\
\hline Average Wage attached Worker & $\bar{w}_{A}$ & 2.54 & \\
\hline Average Wage non-attached Worker & $\bar{w}_{N A}$ & 2.72 & \\
\hline
\end{tabular}

\subsection{Comparative statics for the 15-64 population}

We are now in a position to study the comparative static properties of the model, with the help of the simple system of equations (Entry) (JC), and (Quit), the equilibrium unemployment relationship of equation (14), and the calibration exercise solved in Table 5. Let us first consider the effect of an increase in $y$, the aggregate productivity. While the formal derivation is left to Appendix 9.6, we may derive the main intuition with the help of Figure 2. The increase in $y$ shifts the quit margin to the right along the job creation curve and induces an increase in $\psi$ and $\theta^{q}$, since the job creation curve does not shift. This implies an increase in job creation, and a reduction in job destruction, as would be the case in any reasonable model of the labor market. Further, participation to the labor market goes up, as witnessed by the unambiguous increase in the entry margin in equation (Entry).

The general equilibrium effect of $b$, the specific income of the unemployed is more interesting. In our theoretical perspective, an increase in $b$ is different from the standard effects in equilibrium models (e.g. Mortensen Pissarides 1999), whereby changes in $b$ simply work

\footnotetext{
${ }^{8}$ The total number of contacts is $x_{0} \psi^{-\eta} V$ (i.e. $x_{0}$ is a scale parameter; then $\eta$ is the elasticity of $\chi(\psi)$, the finding rate of workers by firms.
} 
Table 6: Changes in Aggregate Productivity

\begin{tabular}{|c|c|c|c|c|c|c|c|c|c|c|}
\hline$y$ & $\psi$ & $\theta^{\nu}$ & $\theta^{q}$ & $u$ & $n$ & $E_{a}$ & $E$ & $\frac{E_{n a}}{E}$ & $\bar{w}_{A}$ & $\bar{w}_{N A}$ \\
\hline 2.61 & 1.00 & 2.47 & 2.84 & 4.60 & 26.00 & 67.55 & 70.60 & 4.32 & 2.54 & 2.72 \\
\hline 2.66 & 1.04 & 2.52 & 2.89 & 4.43 & 25.27 & 68.35 & 71.42 & 4.29 & 2.59 & 2.77 \\
\hline 2.71 & 1.08 & 2.57 & 2.95 & 4.27 & 24.57 & 69.14 & 72.21 & 4.26 & 2.64 & 2.83 \\
\hline 2.76 & 1.13 & 2.62 & 3.01 & 4.12 & 23.88 & 69.90 & 72.98 & 4.23 & 2.69 & 2.88 \\
\hline 2.81 & 1.17 & 2.67 & 3.06 & 3.98 & 23.21 & 70.64 & 73.73 & 4.19 & 2.74 & 2.93 \\
\hline \multicolumn{11}{|c|}{$\begin{array}{l}u \text { is the unemployment rate; } n \text { is the non participation rate } \\
E_{a}, E_{n a}, \text { and } E \text { are respectively attached, non-attached, and total employment. } \\
\bar{w}_{a} \text { and } \bar{w}_{n a} \text { are the average wage of attached and non-attached workers } \\
\text { Source: Authors' calculation }\end{array}$} \\
\hline
\end{tabular}

Table 7: Changes in Unemployed Income

\begin{tabular}{|c|c|c|c|c|c|c|c|c|c|c|}
\hline$b$ & $\psi$ & $\theta^{\nu}$ & $\theta^{q}$ & $u$ & $n$ & $E_{a}$ & $E$ & $\frac{E_{n a}}{E}$ & $\bar{w}_{A}$ & $\bar{w}_{N A}$ \\
\hline 1.29 & 1.00 & 2.47 & 2.84 & 4.60 & 26.00 & 67.55 & 70.60 & 4.32 & 2.54 & 2.72 \\
1.45 & 0.87 & 2.48 & 2.82 & 4.94 & 26.09 & 67.43 & 70.27 & 4.04 & 2.54 & 2.71 \\
1.61 & 0.74 & 2.49 & 2.80 & 5.35 & 26.18 & 67.26 & 69.87 & 3.73 & 2.55 & 2.71 \\
1.77 & 0.62 & 2.50 & 2.79 & 5.88 & 26.28 & 67.03 & 69.39 & 3.41 & 2.55 & 2.70 \\
1.93 & 0.49 & 2.51 & 2.77 & 6.59 & 26.39 & 66.67 & 68.76 & 3.04 & 2.56 & 2.69 \\
\hline
\end{tabular}

like a reduction in $y$, implying a lower job finding rate, $\psi \chi(\psi)$, and an increase in equilibrium unemployment. The comparative static results show that the increase in $b$ reduces the job finding probability, raises the entry margin $\theta^{v}$, and reduces the quit margin $\theta^{q}$. In terms of Figure 2, this corresponds to a shift of job creation to the right, with a simultaneous shift to the left of the quit margin. The economics of this effect is as follows. Higher $b$ has a direct impact on wages, and reduces job creation and vacancy posting.

The effect on $\theta^{v}$ is a priori ambiguous: it is the sum of a positive direct effect (through Entry) and a negative general equilibrium effect working through a lower $\psi$ already discussed. The analytical results however show that $\theta^{v}$ unambiguously rises in response to $b$. Further, $b$ has a negative effect on $\theta^{q}$, as shown in Appendix 9.6. Table 7 simulates the comparative static effects of $b$ in the general model, using the calibrated economy in Table 5 . The quantitative example suggests that increasing $b$ by as much as 50 percent causes a substantial negative impact on $\psi$, a small positive impact on $\theta^{\nu}$ and a small negative effect on $\theta^{q}$. Since there is a decrease in job creation ( $\psi$ falls) and an increase in job destruction $\left(\theta^{q}\right.$ falls), equilibrium unemployment rises. Further, Table 7 shows that $b$ has a very small effect on total employment, since its main effect is to change the composition of employment with more attached and fewer unattached workers as $b$ rises.

\section{Labor market participation and unemployment}

Our model has three margins, whereas the search-matching literature usually deals with two margins, the job creation and the job destruction margins. We are more accurate regarding the description of the labor supply side of the economy. The first margin, the entry margin 
(Entry), is a decision of workers only, who decide to look for a job or enjoy home productivity. It is thus a pure labor supply margin. The second one, the quit margin (Quit), is a joint decision of the pair worker-firm: when the surplus of the match goes to zero, the decision to destroy the match is jointly efficient. In that sense, the quit margin is not a pure labor supply margin, but rather a mix of labor supply and labor demand. This is a direct result of the wage rule that shares the surplus in fixed proportion $\beta$ and $1-\beta$. If we were to solve the model with fixed wages, the quit margin would no longer be a jointly efficient decision, as the firm would no longer be able to retain a worker willing to quit. ${ }^{9}$ Finally, the job creation margin (JC) is a decision of the firm only, and thus belongs to the labor demand side.

In what follows, we discuss the first two margins considering what happens when labor market frictions disappear, and we show that our model converges to a simple frictionless home productivity model, traditionally solved in the real business cycle literature. Next, we discuss a special case of the model, a situation in which the distribution of $\theta$ has two mass points, and we formally show how the equilibrium of the model, notably unemployment and participation, depends on the distribution and frequency of home productivity shocks.

Thirdly, we show how in such a stylized world, taxation of market activities, neutral in absence of unattachment, may adversely affect the market economy, by endogenously inducing unattachment in equilibrium. Finally, we discuss the dual problem of subsidies to inactivity.

\subsection{Properties of labor supply margins}

In general equilibrium, an increase of the scale parameter $x_{0}$ of the matching function to infinity in equation (13) leads to the convergence of $\theta^{q}$ and $\theta^{\nu}$ to a common limit. Further, using (Quit), one can see that the limit of these two cutoff values is simply $y$, the value of the market productivity. The intuition for this limit result is simple: when frictions disappear, the individual who is indifferent between market and non market activities must get a market reward which is as good as her private return. Indeed, by virtue of wage bargaining, the wage of a market with infinite exit rate from unemployment is simply the flows of profit, and workers receive their marginal product. This implies that $w=y=\theta^{q}$. When $x_{0}$ rises indefinitely, individuals can be inactive or employed, but never unemployed, since the instantaneous probability of finding a job converges to 1 . In this latter case, the common limit $y$ splits the distribution $F$ into individuals that are employed and non employed.

An increase in $x_{0}$ reduces the quit margin, since the joint value of a job is now lower. However, larger $x_{0}$ makes participation to the labor market more attractive, since the probability of finding a job increases. At infinity, the two margins converge to $y$. An interesting feature of our economy is that the share of unattached workers in the population, which writes $F\left(\theta^{q}\right)-F\left(\theta^{\nu}\right)$, converges to zero as $x_{0}$ rises indefinitely. These mechanisms are illustrated in Figure 5 in the Appendix, which reports the general equilibrium values of $\left(\theta^{\nu}, \theta^{q}\right)$ against $x_{0}$.

\footnotetext{
${ }^{9}$ In which case the quit margin would become a pure labor supply margin as the entry margin. See Section 7.1 for an application of this concept in the context of asymmetric information.
} 


\subsection{The transition from full-attachment to unattachment in a spe- cial case}

The derivation of general equilibrium highlighted the relation between equilibrium unemployment and a new set of parameters, linked to the frequency and the distribution of home productivity shocks. In this and the following subsections we explicit the dependence of equilibrium unemployment to such parameters. To study these relationships in the simplest possible model, let us assume that the distribution of $\theta$ 's is degenerate and has two mass points $\theta_{L}<\theta_{H}$, and let us denote with $\alpha_{L}$ and $\alpha_{H}$ the shares of the population in each group (obviously $\alpha_{L}+\alpha_{H}=1$ ). The next subsection will show that a proportional taxation to market activity, neutral in standard models of the labor market, adversely affects unemployment when unattachment exists in equilibrium.

In the particular case considered here, the margins $\theta^{\nu}$ and $\theta^{q}$ are still well defined, and what matters in this example is how they are situated with respect to the mass points $\theta_{L}$ and $\theta_{H}$. The most interesting case is the one in which the high home-productivity level is larger than the unemployed income, but lower than market productivity. In what follows, we assume that $\theta_{L}<b<\theta_{H}<y$, and study two different equilibrium configurations. We refer to the full-attachment equilibrium (case A) when $\theta_{L}<\theta_{H}<\theta^{\nu}$, or simply when all individuals in the working age population are in the labor force. Further, we will study the unattachment equilibrium (case B), where $\theta_{L}<\theta^{\nu}<\theta_{H}<\theta^{q}$, a situation in which individuals in $\theta_{H}$ are in the labor force only when they have a job. One obtains (Appendix 9.8) a single equation determining market tightness $\psi$ which can be written as

$$
\frac{r+\delta}{1-\beta} \frac{c}{\chi(\psi)}+\frac{c \beta}{(1-\beta)} \psi\left(1-i_{B} \alpha_{H} \frac{\lambda}{r+\lambda+\delta}\right)=y-b-i_{B} \alpha_{H}\left(\theta_{H}-b\right) \frac{\lambda}{r+\lambda+\delta},
$$

where $i_{B}$ is an indicator variable equal to zero in the full-attachment equilibrium (A) and 1 in the unattachment equilibrium (B).

One can immediately stress that in the attached equilibrium, $\psi$ does not depend on $\lambda$, nor on the distribution parameters $\theta_{H}$ and $\alpha_{H}$ as in a standard macro matching model with fixed labor force participation. Conversely, in the unattached equilibrium all the parameters linked to the home productivity shocks enter the determination of unemployment. It is notably easy to derive (in Appendix 9.8 again) that in the unattachment equilibrium, the following general equilibrium results hold

$$
\frac{d \psi}{d \lambda}<0 ; \quad \frac{d \psi}{d \theta_{H}}<0 ; \quad \frac{d \psi}{d \alpha_{H}}<0 ; \quad \text { if } i_{B}=1 .
$$

Equilibrium unemployment rises with the arrival rate of household shocks, with the level of home productivity $\theta_{H}$ and with the proportion of individuals in the high productivity state. This shows the interaction between market unemployment, labor demand and non market parameters. Higher $\lambda$ implies that a newly hired individual, who is attached by definition, is more likely to become unattached, with adverse effects on the expected wage costs. This, in turn, reduces labor demand and vacancy posting. Equilibrium unemployment (in the unattached equilibrium it is simply $u=\frac{\delta}{\delta+p(\psi)}$ ) rises when $\psi$ decreases. Other results concerning participation are derived and discussed in Appendix. 


\subsection{Taxation on activity and job creation}

Empirical studies on the cross country determinants of unemployment (e.g. Nickell and Layard, 1999) find a negative relationship between taxation and both unemployment and labor input. In their cross-country reduced form regressions that control for a large set of institutional measures, Nickell and Layard find that the overall tax burden has a clear negative impact on unemployment and on the employment population ratios. They estimate that a reduction in the total tax rate of 5 percentage points would reduce unemployment by 13 percent (e.g. from 8 percent to 7 percent). Similarly, they find adverse effects of taxation on an index of total labor supply, which takes into account differences in the number of hours worked in a given year. More substantial unemployment effects were found by other similar studies, including Daveri and Tabellini (2000) and Scarpetta (1996). Thus, when they review the existing evidence, Nickell and Layard conclude that the balance of the evidence suggests that there is some overall adverse effect of taxation on unemployment and labor input.

Nevertheless, there is some skepticism over this relationship. Several authors believe that the correlation between taxation and unemployment is spurious, since it is difficult to find a negative long run effect of taxation on labor costs. The latter point can be illustrated both empirically and theoretically. First, labor market theories predict that taxation should have no employment effects as long as its effects is entirely borne on wages, with no impact on total labor costs (Pissarides, 1998). Second, several papers estimated country-specific time series regressions on aggregate labor costs, and found that wages tend to adjust, in the very longrun, to changes in taxation. In other words, despite its empirical relevance, the literature has failed to outline a sound transmission mechanism linking taxation to unemployment.

We can rationalize the empirical literature in the context of our model. Although we can do it through simulations in the general case, we can easily illustrate this using the distinction between the two types of equilibria considered above. In what follows, we consider the effect on unemployment stemming from a proportional increase of taxes levied on all market activities. Almost by definition, the non-market activities cannot be taxed instead.

Working with the same discrete distribution specified in the previous subsection, let us assume that market productivity, unemployed income and firms' vacancy costs are all taxed at rate $\tau$. In other words, in a world with proportional taxation we will have $y^{\prime}=(1-\tau) y$, $c^{\prime}=(1-\tau) c$ and $b^{\prime}=(1-\tau) b{ }^{10} \quad$ Substituting these values into equation (15), we still have our two different equilibria, depending on the value of the indicator function $i_{B}$. Let us consider the effect of taxation on the attached equilibrium. In the attached equilibrium an increase in proportional taxation $\tau$ has no effect on market tightness, and no effect on equilibrium unemployment. This is not surprising, since such neutrality is a standard results of two states constant returns to scale models. As long as taxes are levied proportionally on all market activities, including unemployment income, there is no relationship between taxes and unemployment. Gross wages are also unchanged.

Nevertheless, as $\tau$ grows out of zero into positive and increasing values, the shadow value

\footnotetext{
${ }^{10}$ The fact that wages are not taxed directly is for simplicity, since taxing wages impacts the effective share of workers who are less demanding. In our specification, i.e. taxing $b$ and $y$, it is easy to see that the net equilibrium wage of the attached workers is then also proportional to $(1-\tau)$.
} 
of market activities relative to non-market activities falls. Indeed, there exists a level of taxation, which we indicate with $\tau^{*}$, such that for all $\tau>\tau^{*}$, the equilibrium switches from attachment to unattachment. Thus, for all $\tau>\tau^{*}$, market tightness solves

$$
\frac{r+\delta}{1-\beta} \frac{c(1-\tau)}{\chi(\psi)}+\frac{c(1-\tau) \beta}{(1-\beta)} \psi\left(1-\alpha_{H} \frac{\lambda}{r+\lambda+\delta}\right)=(y-b)(1-\tau)-\alpha_{H}\left(\theta_{H}-b\right) \frac{\lambda}{r+\lambda+\delta}
$$

where $\tau^{*}$ is defined as

$$
b\left(1-\tau^{*}\right)+\frac{c\left(1-\tau^{*}\right) \beta}{(1-\beta)} \psi(a)=\theta_{H}
$$

and $\psi(a)$ is the market tightness of the attached equilibrium. In the unattached equilibrium, described by equation (17), proportional taxation on market activity has an adverse impact on equilibrium unemployment. These results are illustrated numerically in the Appendix (see Figure 6). Thus, beyond $\tau^{*}$ unemployment is higher and participation is lower. Note that the example of this Section is constructed in such a way that taxation affects $\psi$, the job creation margin. ${ }^{11}$ In terms of wages, the gross wage for the attached workers falls, while the gross wage of the unattached workers increases. This implies that the overall effect of taxation on the average wage is ambiguous, in line with what the empirical literature seems to find. The mechanism outlined in this Section, linking taxation to unemployment via its effect on the value of inactivity is important and novel.

\subsection{The value of inactivity and the incentives to work}

In the previous subsection, we showed how taxation of labor activities reduces the incentives to work. The model can also illustrate the dual problem of how benefits to inactive people change the participation decisions. A recent OECD study (OECD 1999) carefully investigates the components of various benefits (unemployment insurance, unemployment assistance, social assistance, family benefits and housing benefits), the tax system and the replacement rate for short-term and long-term benefit recipients. Except for the unemployment insurance, the other components described above belong to what we call in this subsection the nonactivity benefits.

The OECD compares the income of the average production worker, the income of the unemployed in the initial phase of benefit receipt and the income of long-term benefit recipients, in various family situations. We use the figures of Tables 3.2 to 3.7 of the OECD study to compute the average replacement rates of both short-term and long-term recipients being either single, or lone parent with two children, and the correlation coefficients of the four series across 26 OECD countries. Table 8 illustrates the difference between the replacement rate of the unemployed workers and the replacement rate of the inactive workers.

\footnotetext{
${ }^{11}$ Alternatively, one could construct an example where $\theta_{H}$ is close to $\theta^{q}$, and an increase in taxation brings the employed workers with $\theta=\theta_{H}$ beyond the quit margin. In this latter case there would then be a discrete jump in job destruction and an increase in unemployment. The basic intuition and the main results would remain the same.
} 
Table 8: Average Replacement Ratios for Short Term and Long Term Benefit Recipients.

\begin{tabular}{|c|c|c|c|c|c|c|}
\hline & Mean & $S D^{a}$ & $(I)^{b}$ & $(I I)$ & $(I I I)$ & $(I V)$ \\
\hline (I) ST, single & 0.59 & 0.14 & 1 & 0.17 & 0.79 & 0.21 \\
\hline (II) LT, single & 0.38 & 0.18 & & 1 & 0.46 & 0.72 \\
\hline (III) ST, lone with two children & 0.69 & 0.13 & & & 1 & 0.59 \\
\hline (IV) LT, lone with two children & 0.57 & 0.16 & & & & 1 \\
\hline \multicolumn{7}{|l|}{ Number of Countries: 26} \\
\hline \multicolumn{7}{|l|}{$S T$ is short term; $L T$ is long term } \\
\hline \multicolumn{7}{|l|}{${ }^{a}$ standard deviation } \\
\hline \multicolumn{7}{|l|}{${ }^{b}$ correlation coefficients } \\
\hline Source: OECD 1999 and Autho & & & & & & \\
\hline
\end{tabular}

As expected, the short-term replacement rates are in average higher than the long-term replacement rates, and higher for the family with two children than for single workers. Perhaps more surprising is the very small correlation (0.17) between short and long-term replacement rates of single worker. This finding suggests that, for this category of workers, one should very carefully disentangle the theoretical effect of unemployment benefits and non-activity benefits when discussing the cross-country unemployment differences: the two sources of income appear to be very much disconnected. The other correlation coefficients of the matrix appear to be higher: countries which are generous with families are also generous with single workers, both in the short-term and the long-term. Finally, the correlation coefficient between short-term and long-term replacement ratios for the family with two children is quite high (0.59). A closer look at the component of these replacement rates shows that the unemployment insurance is the largest fraction of the income of the short-term recipients while it is negligible in all countries (but Austria) for long-term recipients. The only explanation for this high correlation coefficient is therefore that inactivity benefits are correlated with the level of unemployment insurance.

What are the implications for the model? In principle, non-activity benefits should add-up to home production to shift the distribution of $\theta^{\prime} s$ to the right. For instance, one could have two measures of income for non-employment: $b$, or the unemployment insurance component, and non-activity benefits denoted by $b_{n}$, a specific income of the non-employed workers. If a fraction $f$ of these benefits goes to the active workers, one should rewrite the utility functions as: $u^{w}=w+f b_{n} ; u^{u}=b+f b_{n}$ while $u^{n}(\theta)=\theta+b_{n}$. Higher $b_{n}$ would imply higher wages, higher fraction of unattached workers, i.e. larger en flows, lower participation to the labor market and higher unemployment. In other words, we have here a potentially powerful explanatory variable for the latter two stock variables. ${ }^{12}$ According to the OECD study referred above, the lowest long-term replacement ratio for families with two children is in the US (0.41) and the highest in Sweden, Austria, Belgium and Denmark (0.75, .077, 0.69 and 0.70), and takes intermediate values in Portugal, Italy, Canada, Germany (0.51, 0.51, $0.58,0.63)$, etc... As we argue in the conclusions, these considerations are very promising for further research on the cross country determinants of unemployment.

Note that this subsection as the previous one can be used to investigate the employment

\footnotetext{
${ }^{12}$ Lower $f$ plays a similar role in raising the gap between labor market income and inactivity income, thus raising unattachment and non-participation.
} 
and participation effect of a negative income tax such as the one being introduced in continental European countries. More generally, our approach allows to discuss workfare issues, and is especially relevant in the context of a high unemployment economy.

\section{$7 \quad$ Further issues}

\subsection{Asymmetric information}

Our modeling perspective ignores the existence of asymmetric information in the employer employee relationship, in a way consistent with most of the matching models. In reality, however, asymmetric information in the worker's specific value of $\theta$ may be relevant. Indeed, a few periods after being hired (a time at which the employer knows that the worker is attached), any worker will have an incentive to claim that she is unattached, has higher outside option, and deserves better wages. We are then in a case in which the workers, having all the information, will be able to capture an informational rent.

There are two ways of deriving the new solution of the model in this case. The first one is to extend our bargaining game over wages along the line of an early paper by Harsanyi and Selten (1972), where two agents bargain in the context of incomplete information. The main result of this analysis is that a unique wage will be offered to all agents, regardless of their unobservable home production. In their paper, both the extensive-form game and the axiomatic solution is derived. Applying the axiomatic solution to our context, the Nashmaximand that would result would be:

$$
\underset{w}{\operatorname{Max}}(1-\beta) \ln J+\beta\left(\int_{\theta_{\min }}^{\widetilde{\theta}^{q}} f(\theta) \ln [(W(\theta)-\operatorname{Max}(U, N(\theta))])\right.
$$

where $\widetilde{\theta}^{q}$ stands for the reservation productivity of workers. Since the wage is unique, some workers with high home productivity will quit although the firm, if it only could know their type, would like to retain them by offering a higher wage. Inefficient separations will occur in this case.

One may not be very comfortable with the reduced form for wages implied by equation (18) especially since one has the feeling that many strategic interactions are left hidden. In addition, the imperfection in information requires us to modify the authority structure of the relationship, and let the firm be wage setter. If labor was perfectly divisible, the firm would be able to infer the type of the workers by offering a menu of contracts in which the agents may either work a lot for a high wage, or work a little for a low wage. In this context, the workers with high productivity at home would choose to work less. In any event, inefficiencies will persist.

Since we have assumed that labor is indivisible, the firm has no way to implement the solution described above. The solution we propose here is the following: since at the time of the initial meeting, the firm knows the worker is attached, but then that all subsequent changes in the workers' types are unobservable (and that no claim by the worker is credible), the wage is set once and for all (i.e. never renegociated) in taking into account the classical 
efficiency wage trade-off: higher wage reduces the flow profits but also turnover and thus partially raises intertemporal profits.

The wage will thus be set unilaterally by the firm and will never be renegotiated. In all cases, inefficient destructions will occur. In this new set-up, the value function of the firm is such that $J(w)=\frac{y-w}{r+\delta+q\left(\widetilde{\theta}^{q}(w)\right)}$ where $q\left(\widetilde{\theta}^{q}(w)\right)=\lambda\left(1-F\left(\widetilde{\theta}^{q}(w)\right)\right)$ and $\widetilde{\theta}^{q}(w)$ is the reservation home productivity of workers, given by $N\left(\widetilde{\theta}^{q}(w)\right)=W\left(w, \widetilde{\theta}^{q}(w)\right)$ or

$$
\frac{\lambda}{r+\lambda+\delta} \int_{\tilde{\theta}^{v}}^{\widetilde{\theta}^{q}(w)} F\left(\theta^{\prime}\right) d \theta^{\prime}=\widetilde{\theta}^{q}(w)-w
$$

It is important to recognize that the entry margin $\widetilde{\theta}^{v}$ is in partial equilibrium independent on the wage set by the firm, although it will obviously depend on the equilibrium wage in general equilibrium. The same remark applies to labor market tightness $\psi$. The firm, being $\psi$ and $\widetilde{\theta}$-taker, thus maximizes $J(w)$ which leads to

$$
\frac{y-w}{r+\delta+q\left(\widetilde{\theta}^{q}\right)} \frac{\partial q\left(\widetilde{\theta}^{q}\right)}{\partial w}=-1
$$

The interpretation is simply that any marginal increase in wage reduces profits by 1 but reduces turnover by $\frac{\partial q\left(\widetilde{\theta}^{q}\right)}{\partial w}$ thus raising the duration of profits $\frac{y-w}{r+\delta+q\left(\widetilde{\theta}^{q}\right)}$.

We can now prove (see Appendix 9.9) the following results: 1) there are inefficient destructions, i.e. $\left.\mathcal{S}\left(\widetilde{\theta}^{q}\right)>0,2\right)$ despite the firm having the control of wages, workers enjoy a rent and 3) as $\lambda$ is closer and closer to zero, the inefficiencies described above tend to disappear: $S\left(\widetilde{\theta}^{q}\right) \rightarrow 0$ and the wage becomes closer from the reservation wage.

To conclude here, the main properties (the entry and the exit margin) still exist with asymmetric information, and both workers and firms enjoy rents. Now, the main difference is the existence of inefficient job destruction. This last property of the model with asymmetric information tends to disappear as the frequency of home productivity shocks goes to zero.

\subsection{Time devoted to job search}

Our general set-up implies that unemployed workers devote all their time to market activities, and do not enjoy any of the benefits stemming from home production. This assumption is fully consistent with the real business cycle literature on non convexity in labor market participation (Rogerson, 1988). However, existing surveys for the US or the UK suggest that the median unemployed worker spends less than 10 hours per week in labor market activities such as job search, interviews, etc. (Layard et al. 1991). Thus, one may want to consider an extended version of our model, and have unemployed workers spending a fraction $e<1$ of their time in labor market activities and $1-e$ in home production. In this latter case, the utility of unemployed would read

$$
u^{u}(\theta)=b+(1-e) \theta
$$


We did solve such a model, and we found that most of the intuition of our model carries through. Appendix 9.2 shows for instance that the main insight of the model (the existence of the reservation strategy and the separate margins $\theta^{q}$ and $\theta^{\nu}$ ) is not a consequence of the simplifying assumption made in the text. The cost is however a much higher complexity. Thus, we decided to keep the assumption $e=1$ throughout the paper. A technical Appendix fully deriving the model with $e<1$ is available on request (Garibaldi and Wasmer 2000).

\subsection{Life-cycle considerations}

Are household shocks a random Poisson process? The technical gain from this assumption is obvious: it allows us to consider steady-state values of Bellman equations and thus offers close form solutions to the model. The loss is that it restricts the interpretation of the model: it can not be considered as a model of life-cycle participation choices (these choices being already well understood in a full-employment world ${ }^{13}$ ). Our model is better at modelling the circumstances under which individuals, in a given period of life (say, women aged 35-44) decide to leave or re-enter the labor market, given family variations in $\theta$ s. To make this point clearer, we consider individuals that have already chosen their life-cycle participation behavior (working in their 20's, marrying in their early 30s, having children and leaving the labor market in their 30's, coming back in their 40's, etc...). Our model only considers what happens in each of the sub-periods, which is determined by $\theta$ shocks, unexpected (though predictable) and also, persistent: at low frequency, Poisson processes generate very persistent series. Our specification appears to be very useful for understanding the structural flows to and from inactivity. Even though we do not introduce life-cycle participation features, the model generates several sensible predictions regarding the flows from and to inactivity.

\subsection{Endogenous job destruction}

We can show that the endogenous destruction margin in Mortensen-Pissarides (1994) is formally equivalent to the endogenous quit margin of our model. It suffices to notice that at $\theta=\theta^{q}$, the value of a job is $J\left(\theta^{q}\right)=0$. Now, if productivity was stochastic and evolved over time, with a value $\varepsilon$, then one would define a reservation productivity $\varepsilon^{d}(\theta)$ such that $J\left(\varepsilon^{d}(\theta), \theta\right)=0$. Equivalently, by inversion, there would be a cutoff value $\theta^{q}(\varepsilon)$ such that $J\left(\varepsilon, \theta^{q}(\varepsilon)\right)=0$. Both definitions of destruction margins are actually equivalent, and thus, our model features endogenous destruction as well, although destruction comes from the labor supply side, rather than from the labor demand side. The solution to this model would however imply one more unknown to solve for, $\varepsilon^{d}\left(\theta^{\nu}\right)$ and the additional complexity would hide the intuitions of our labor supply model.

\footnotetext{
${ }^{13}$ e.g., see Ben Porath (1967) for labor supply and education; Weiss (1986) for labor supply and life-cycle earnings.
} 


\section{Conclusions}

Our theoretical perspective suggests several avenues for further research. The simple three states theory of the labor market that we propose can be used quantitatively for calibrating the cross country differences in labor market participation and unemployment, in a way consistent with the recent work on unemployment differences by Mortensen and Pissarides (1999). We have shown the strong and neglected links between equilibrium unemployment and the distribution and frequency of shocks to non-market activities. In our view, this is a very important result.

It is important to remark that the political agenda after the 2000 extraordinary council of the European Union in Lisbon switched focus from reducing unemployment to raising employment rates up to 75 percent. In this respect, our theory is especially appropriate for addressing these issues. Indeed, as Table 2 showed, to understand employment one has to understand the determinants of participation, among which the value of inactivity, the taxation of activity, the level of relative wages and the equilibrium level of unemployment takes centre stage. In high unemployment economies, analyzing the related workfare issues is impossible unless one uses our three states approach.

To conclude, we have not found in the literature comparative studies attempting at estimating the lifetime value of inactivity for different countries, nor we have found studies that evaluate the impact of country specific (welfare-state) institutions, such as early retirement programs, educational policies, etc... on the value of inactivity. If some research was undertaken in this direction, one could investigate empirically the positive links between unemployment and the value of inactivity, as it is predicted by our theory. Finally, the impact of various labor market institutions on labor force participation should be more carefully studied, both empirically and theoretically. Then, the persistence of large rates on unemployment and low participation rates in Europe may ultimately become a much less controversial issue. 


\section{Appendix}

\subsection{Bellman equations}

With the use of the threshold values $\theta^{\nu}$ and $\theta^{q}$, one can rewrite the value functions as:

$$
\begin{aligned}
\theta & \leq \theta^{\nu} \Rightarrow \\
(r+\lambda) W(\theta) & =u^{w}+\delta(U-W)(\theta)+\lambda \int_{\theta^{\min }}^{\theta^{q}} W\left(\theta^{\prime}\right) d F\left(\theta^{\prime}\right)+\lambda \int_{\theta^{q}}^{\theta^{\max }} N\left(\theta^{\prime}\right) d F\left(\theta^{\prime}\right) \\
\theta^{\nu} & \leq \theta \leq \theta^{q} \Rightarrow \\
(r+\lambda) W(\theta) & =u^{w}+\delta(N-W)(\theta)+\lambda \int_{\theta^{\min }}^{\theta^{q}} W\left(\theta^{\prime}\right) d F\left(\theta^{\prime}\right)+\lambda \int_{\theta^{q}}^{\theta^{\max }} N\left(\theta^{\prime}\right) d F\left(\theta^{\prime}\right) \\
\theta & \leq \theta^{\nu} \Rightarrow \\
(r+\lambda) U(\theta) & =u^{u}+p(W-U)(\theta)+\lambda \int_{\theta^{\min }}^{\theta^{\nu}} U\left(\theta^{\prime}\right) d F\left(\theta^{\prime}\right)+\lambda \int_{\theta^{\nu}}^{\theta^{\max }} N\left(\theta^{\prime}\right) d F\left(\theta^{\prime}\right) \\
\theta^{q} & \leq \theta \Rightarrow \\
(r+\lambda) N(\theta) & =u^{n}+\lambda \int_{\theta^{\min }}^{\theta^{\nu}} U\left(\theta^{\prime}\right) d F\left(\theta^{\prime}\right)+\lambda \int_{\theta^{\nu}}^{\theta^{\max }} N\left(\theta^{\prime}\right) d F\left(\theta^{\prime}\right)
\end{aligned}
$$

\subsection{Slopes of value functions}

We prove the existence of the reservation properties in the most general case when, in the spirit of our technical appendix (Garibaldi and Wasmer 2000), the utility flows of the agents depend in each state of their individual $\theta$. We then explain what happens when we restrict the utility to the simpler formulation of the text. As argued here, this property, presumably the most important of the model, does not rely on the complete indivisibility of labor.

To solve for the reservation values of $\theta$ we proceed in two steps. First, making use of the relationships in (21-27), we study the slopes of the value functions. We claim that the value functions are piecewise linear functions of $\theta$, with constant derivatives in each interval. Second, we use this slopes to solve for the respective value functions and obtain the equilibrium values of $\theta^{\nu}$ and $\theta^{q}$.

Differentiating the results with respect to $\theta$ yields the following results (denoting by $u_{\theta}^{i}=\partial u^{i}(\theta) / \partial \theta$ for $i=w, u, n)$ :

$$
\begin{aligned}
\frac{\partial W}{\partial \theta} & =\frac{r+\lambda+p}{(r+\lambda+\delta+p)(r+\lambda)} u_{\theta}^{w}+\frac{\delta}{(r+\lambda)(r+\lambda+\delta+p)} u_{\theta}^{u} \quad \text { for } \quad \theta \leq \theta^{\nu}, \\
\frac{\partial W}{\partial \theta} & =\frac{1}{r+\lambda+\delta} u_{\theta}^{w}+\frac{\delta}{(r+\lambda)(r+\lambda+\delta)} u_{\theta}^{n} \quad \text { for } \quad \theta^{\nu} \leq \theta \leq \theta^{q}, \text { and } \\
\frac{\partial U}{\partial \theta} & =\frac{r+\lambda+\delta}{(r+\lambda+\delta+p)(r+\lambda)} u_{\theta}^{u}+\frac{p}{(r+\lambda)(r+\lambda+\delta+p)} u_{\theta}^{w} \quad \text { for } \quad \theta \leq \theta^{\nu}, \text { and } \\
\frac{\partial N}{\partial \theta} & =\frac{1}{r+\lambda} u_{\theta}^{n} \quad \text { for } \theta \geq \theta^{\nu}
\end{aligned}
$$




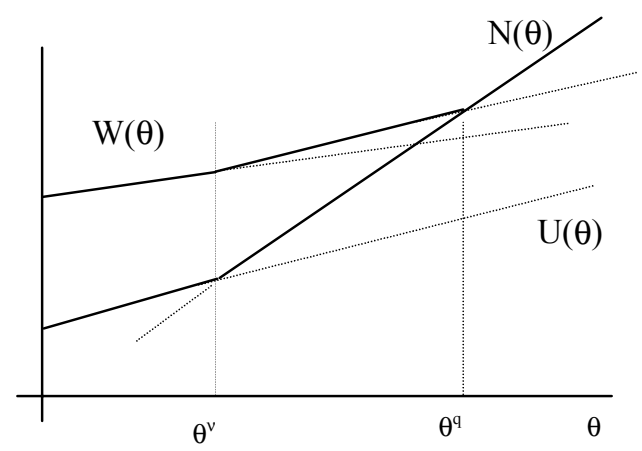

Figure 4: Value Functions with Linear Utilities

If one further assumes that the utility flows are linear functions of $\theta$, with the following ranking $^{14}$ :

$$
\begin{aligned}
u_{\theta}^{w(\text { attached })} & <u_{\theta}^{u}<u_{\theta}^{n} \\
u_{\theta}^{w(\text { attached })} & <u_{\theta}^{w(\text { unattached })}
\end{aligned}
$$

one has, in Figure 4, an illustration of the relative positions of the asset values in the three states as a function of $\theta$.

It follows that the (negative of) the slope of the surplus is given by:

$$
\begin{aligned}
& s_{a}=\frac{-\partial(W-U)}{\partial \theta}=\frac{u_{\theta}^{u}-u_{\theta}^{w}}{r+\lambda+\delta+p} \quad \text { for } \quad \theta \leq \theta^{\nu}, \\
& s_{n a}=\frac{-\partial(W-N)}{\partial \theta}=\frac{u_{\theta}^{n}-u_{\theta}^{w}}{r+\lambda+\delta} \quad \text { for } \quad \theta^{\nu} \leq \theta \leq \theta^{q}, \text { and } \\
& s_{n a}>s_{a}>0 .
\end{aligned}
$$

The last inequality comes from:

$$
s_{a}-s_{n a}=\frac{(r+\lambda+\delta)\left(u_{\theta}^{u}-u_{\theta}^{n}\right)-p\left(u_{\theta}^{n}-u_{\theta}^{w}\right)}{(r+\lambda+\delta)(r+\lambda+\delta+p)}<0
$$

given the assumption on rank of the partial derivatives $u_{\theta}^{i}$.

$N B$ : when we assume that $u^{u}(\theta)$ does not depend on $\theta$, then wages can be shown to be independent of $\theta$ for $\theta \leq \theta^{\nu}$. Then, this implies that $s_{a} \equiv 0$, and in addition that the value function $U(\theta)$ and $W(\theta)$, for $\theta \leq \theta^{\nu}$, are constant of $\theta$. In this case, the asset values in Figure 4 are flat for $U$ and the attached part of $W$, and increasing for $N$ and the unattached part of $W$.

\footnotetext{
${ }^{14}$ Note that, in our technical appendix, we show that for the attached workers, $\partial w / \partial \theta=(1-\alpha) u_{\theta}^{u}$ with $\alpha=\alpha(p)=\beta \frac{1+\frac{p}{r+\lambda+\delta}}{1+\frac{\beta p}{r+\lambda+\delta}} \geq \beta$ and for the unattached workers, $\partial w / \partial \theta=(1-\beta) u_{\theta}^{n}$. So, under the reasonable assumption that $u_{\theta}^{u}<u_{\theta}^{n}$, all other inequalities listed here follow.
} 


\subsection{Derivation of wages}

Using (10), one has

$$
\begin{aligned}
w_{A}(\theta) & =(1-\beta)(b+p(\psi)(W-U))+\beta y \quad \forall \theta \leq \theta^{\nu} \\
w_{N A}(\theta) & =(1-\beta) \theta+\beta y \quad \forall \theta: \theta^{\nu} \leq \theta \leq \theta^{q}
\end{aligned}
$$

where $w_{A}(\theta)$ is the attached wage and $w_{N A}(\theta)$ is the non attached wage. As usual, the wage is a weighted average of the outside option of workers and their marginal product. The dependence of the wage to the outside option implies that there are two distinct expressions, one for the attached, one for the unattached workers, since their outside option is different. Using the fact that $W-U=$ $W\left(\theta^{\nu}\right)-U\left(\theta^{\nu}\right)$ for $\theta<\theta^{\nu}, J^{e}=J\left(\theta^{\nu}\right)$, noting that $\lambda \beta \int_{\theta^{\min }}^{\theta^{q}}\left[J\left(\theta^{\prime}\right)-V_{V}\right] d F\left(\theta^{\prime}\right)=\lambda(1-\beta) \overline{S_{w}}$ given Nash-bargaining, and

$$
(1-\beta) p(\psi)(W-U)=\beta p(\psi) J^{e}=\beta c \psi
$$

the two wage rules read simply as in equations (11) and (12). Finally, to obtain $w_{N A}=w_{A}+$ $\left(\theta-\theta^{\nu}\right)(1-\beta)$, one can use an integration by parts of $J(\theta)$.

\subsection{Slopes of the curves in general equilibrium.}

Differentiation of equation (JC) after replacing $\theta^{\nu}$ by its value and denoting by $\eta(\psi)$ the negative of the elasticity of $\chi$ with respect to $\psi, \eta(\psi)=-\psi \chi^{\prime} / \chi$ :

$$
\frac{\partial \theta^{q}}{\partial \psi}=\frac{c \eta(\psi)}{\psi \chi(\psi)} \frac{r+\lambda+\delta}{1-\beta}+\frac{c \beta}{1-\beta}>0
$$

whereas, proceeding similarly for equation (Quit), one obtains instead

$$
\frac{\partial \theta^{q}}{\partial \psi}=\frac{-\lambda F\left(\theta^{\nu}\right)}{r+\delta+\lambda\left(1-F\left(\theta^{\nu}\right)\right)} \frac{c \beta}{1-\beta}<0
$$

which yields a negative relationship between $\psi$ and $\theta^{q}$.

\subsection{Steady-state stocks}

One can write the evolution of the stocks of workers in the three categories by:

$$
\begin{aligned}
d E_{a} / d t & =-\left(e_{a} n+e_{a} u+e_{a} e_{n a}\right) E_{a}+u e_{a} U+e_{a} e_{n a} E_{n a} \\
d E_{n a} / d t & =-\left(e_{n a} n+e_{n a} u+e_{n a} e_{a}\right) E_{n a}+e_{a} e_{n a} E_{n a} \\
d U / d t & =-\left(u e_{a}+u n\right) U+e_{a} u E_{a}+n u N \\
d N / d t & =-n u N+e_{n a} n E_{n a}+u n U+e_{a} n E_{a}
\end{aligned}
$$


In steady-state and replacing the rates of transition by their values, one obtains:

$$
\begin{aligned}
N \lambda F\left(\theta^{\nu}\right)-\lambda U\left(1-F\left(\theta^{\nu}\right)\right) & =\lambda E_{a}\left(1-F\left(\theta^{q}\right)\right)+E_{n a}\left(\delta+\lambda-\lambda F\left(\theta^{q}\right)\right) \\
U\left(\lambda-\lambda F\left(\theta^{\nu}\right)+p\right) & =N \lambda F\left(\theta^{\nu}\right)+E_{a} \delta \\
E_{a}\left(\delta+\lambda-\lambda F\left(\theta^{\nu}\right)\right) & =p U+E_{n a} \lambda F\left(\theta^{\nu}\right) \\
E_{n a}\left(\delta+\lambda-\lambda F\left(\theta^{q}\right)+\lambda F\left(\theta^{\nu}\right)\right) & =\lambda E_{a}\left(F\left(\theta^{q}\right)-F\left(\theta^{\nu}\right)\right) \\
E_{n a}+E_{a}+U+N & =1
\end{aligned}
$$

Take $(37)+(38)$, and denote by $E=E_{a}+E_{n a}$. One gets:

$$
E\left(\delta+\lambda-\lambda F\left(\theta^{q}\right)\right)=p U
$$

which immediately leads to

$$
u=\frac{\delta+q}{\delta+p+q}
$$

where

$$
q=\lambda\left(1-F\left(\theta^{q}\right)\right)
$$

Then, using (38), one has that

$$
\frac{E_{a}}{E}=\frac{\delta+q+\lambda F\left(\theta^{\nu}\right)}{\delta+q+\lambda F\left(\theta^{q}\right)}=\frac{\delta+q+\lambda F\left(\theta^{\nu}\right)}{\delta+\lambda}
$$

and thus

$$
\frac{E_{n a}}{E}=\frac{\lambda\left(F\left(\theta^{q}\right)-F\left(\theta^{\nu}\right)\right)}{\delta+\lambda}
$$

Finally, using (36), one has:

$$
N \lambda F\left(\theta^{\nu}\right)=\left(\lambda-\lambda F\left(\theta^{\nu}\right)+p\right) U-\delta\left(\frac{\delta+q+\lambda F\left(\theta^{\nu}\right)}{\delta+\lambda} E\right)
$$

which, dividing by $E+U=1-n$ where $n$ is the non-participation rate, leads to

$$
\begin{aligned}
\frac{N}{E+U} \lambda F\left(\theta^{\nu}\right) & =\left(\lambda-\lambda F\left(\theta^{\nu}\right)+p\right) u-\delta\left(\frac{\delta+q+\lambda F\left(\theta^{\nu}\right)}{\delta+\lambda}\right)(1-u) \quad \text { or } \\
\frac{n}{1-n} \lambda F\left(\theta^{\nu}\right) & =\left(\lambda-\lambda F\left(\theta^{\nu}\right)+p\right) \frac{\delta+q}{\delta+p+q}-\delta\left(\frac{\delta+q+\lambda F\left(\theta^{\nu}\right)}{\delta+\lambda}\right) \frac{p}{\delta+p+q}
\end{aligned}
$$

which, even using $q=\lambda-\lambda F\left(\theta^{q}\right)$, can't be simplified easily. 


\subsection{Comparative static}

Working with the three key equations (JC), (Entry) and (Quit), we define the following matrix of partial derivatives with respect to $\psi, \theta^{\nu}, \theta^{q}$

$$
A=\left(\begin{array}{ccc}
-\frac{c \chi^{\prime}(\psi)}{\chi^{2}(\psi)} ; & \frac{(1-\beta)}{(r+\lambda+\delta)} ; & -\frac{(1-\beta)}{(r+\lambda+\delta)} ; \\
-\frac{\beta c}{(1-\beta)} ; & 1 ; & 0 \quad ; \\
0 \quad ; & \frac{\lambda F\left(\theta^{\nu}\right)}{r+\lambda+\delta} ; & \frac{\lambda\left(1-F\left(\theta^{q}\right)\right)+r+\delta}{r+\lambda+\delta} ;
\end{array}\right) .
$$

For obtaining the comparative static effects of $b$ and $y$, we apply Kramer's rule to the system JC Entry and Quit. Since $|A|>0$ the derivatives of the three margins with respect to $y$ yield

$$
\begin{aligned}
\frac{d \psi}{d y} & =\frac{(1-\beta)}{|A|(r+\lambda+\delta)}>0 \\
\frac{d \theta^{\nu}}{d y} & =\frac{\beta c}{|A|(r+\lambda+\delta)}>0 \\
\frac{d \theta^{q}}{d y} & =-\frac{c \chi^{\prime}(\psi)}{|A| \chi^{2}(\psi)}+\frac{\beta c}{|A|(r+\lambda+\delta)}>0 .
\end{aligned}
$$

Similarly, the derivatives of the three endogenous margins with respect to $b$ yield

$$
\begin{aligned}
\frac{d \psi}{d b} & =-\frac{(1-\beta)}{|A|(r+\lambda+\delta)}<0 \\
\frac{d \theta^{\nu}}{d b} & =-\frac{c \chi^{\prime}(\psi)}{|A| \chi^{2}(\psi)} \frac{\lambda\left(1-F\left(\theta^{q}\right)\right)}{(r+\lambda+\delta)}>0 \\
\frac{d \theta^{q}}{d b} & =\frac{c \chi^{\prime}(\psi)}{|A| \chi^{2}(\psi)} \frac{\lambda F\left(\theta^{\nu}\right)}{(r+\lambda+\delta)}<0
\end{aligned}
$$

\subsection{Labor supply : numerical resolutions}

\subsubsection{The convergence of the entry and exit margins.}

Figure 5 suggests that more depressed economies (i.e. with lower scale $x_{0}$ and lower job finding rate $p d t)$ are characterized by a larger fraction of unattached workers.

\subsubsection{The effect of taxation}

In line with the equations discussed in Section 6.3, Figure 6 illustrates the sudden increase in unemployment when taxation raises up to the threshold point at which the equilibrium is an unattached one.

\subsection{Market tightness and home productivity shocks}

In the full-attachment equilibrium (case A) when $\theta_{L}<\theta_{H}<\theta^{\nu}$, one has that $F=1$ between $\theta^{\nu}$ and $\theta^{q}$, and then from equation (Quit), the quit margin rewrites

$$
\theta^{q}-y=\frac{\lambda}{r+\lambda+\delta}\left(\theta^{q}-\theta^{\nu}\right)
$$




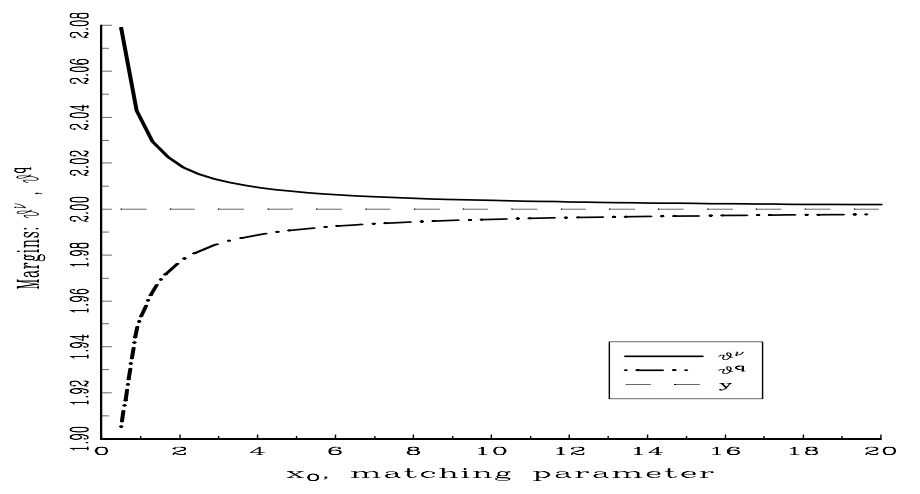

Figure 5: $\theta^{v}$ and $\theta^{q}$ for different matching scale parameters

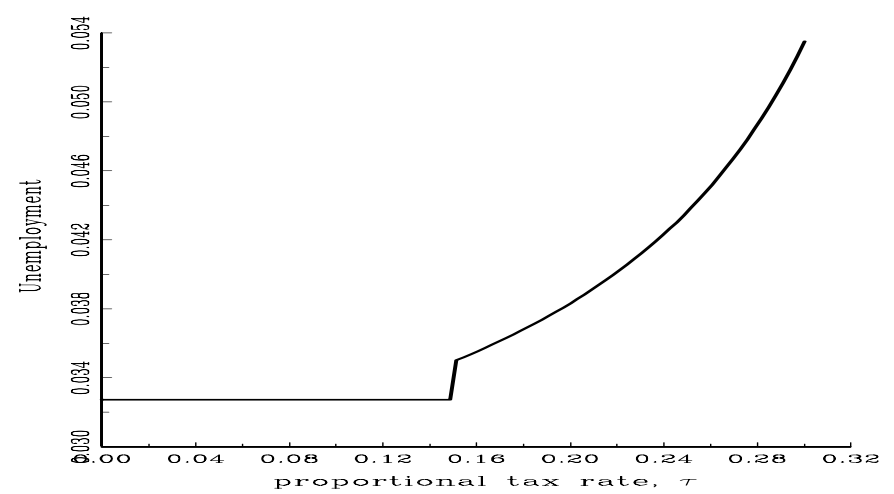

Figure 6: Proportional taxation, unattachment, and equilibrium unemployment 
In the unattachment equilibrium (case B), where $\theta_{L}<\theta^{\nu}<\theta_{H}<\theta^{q}$, one has that $F=\alpha_{L}$ between $\theta^{\nu}$ and $\theta_{H}$ and 1 above. From equation (Quit), the quit margin rewrites

$$
\theta^{q}-y=\frac{\lambda}{r+\lambda+\delta}\left[\left(\theta^{q}-\theta^{\nu}\right)-\alpha_{H}\left(\theta_{H}-\theta^{\nu}\right)\right] .
$$

Combining these equations with the two other general equilibrium equations (Entry) and (JC), one obtains the equation (15) of the text. While equation (15) fully determines the equilibrium market tightness $\psi$, the unattachment equilibrium requires also that $N\left(\theta_{H}\right)>U\left(\theta_{H}\right)$ or that

$$
\theta_{H} \geqslant \theta^{v}=b+\frac{\beta c \psi}{1-\beta}
$$

The inverse relationship must hold in the attached equilibrium.

In this discrete version of the model, the unattached equilibrium is thus the solution to

$$
\frac{r+\delta}{1-\beta} \frac{c}{\chi(\psi)}+\frac{c \beta}{(1-\beta)} \psi\left(1-\alpha_{H} \frac{\lambda}{r+\lambda+\delta}\right)=y-b-\alpha_{H}\left(\theta_{H}-b\right) \frac{\lambda}{r+\lambda+\delta}
$$

where $\psi$ simultaneously solves

$$
\theta_{H}>\left(b+\frac{\beta c \psi}{1-\beta}\right)=\theta^{v}
$$

There are three comparative static results. First $\frac{d \psi}{d \lambda}<0$. Differentiating equation (44) with respect to $\lambda$ and rearranging yields

$$
\left[-\frac{r+\delta}{1-\beta} \frac{c \chi(\psi)}{\chi(\psi)}+\frac{c \beta}{(1-\beta)} \frac{r+\lambda\left(1-\alpha_{H}\right)+\delta}{r+\lambda+\delta}\right] \frac{d \psi}{d \lambda}=\frac{(r+\delta) \alpha_{H}}{(r+\lambda+\delta)^{2}}\left[b+\frac{c \beta}{(1-\beta)} \psi-\theta_{H}\right] .
$$

Making use of equation (45) the result immediately follows. Second $\frac{d \psi}{d \theta_{H}}<0$. Differentiating equation (44) with respect to $\theta_{H}$ and rearranging yields

$$
\left[-\frac{r+\delta}{1-\beta} \frac{c \chi(\psi)}{\chi(\psi)}+\frac{c \beta}{(1-\beta)} \frac{r+\lambda\left(1-\alpha_{H}\right)+\delta}{r+\lambda+\delta}\right] \frac{d \psi}{d \theta_{H}}=-\frac{\lambda \alpha_{H}}{r+\lambda+\delta} .
$$

Third $\frac{d \psi}{d \alpha_{H}}<0$.Differentiation equation (44) with respect to $\alpha_{H}$ and rearranging yields

$$
\left[-\frac{r+\delta}{1-\beta} \frac{c \chi(\psi)}{\chi(\psi)}+\frac{c \beta}{(1-\beta)} \frac{r+\lambda\left(1-\alpha_{H}\right)+\delta}{r+\lambda+\delta}\right] \frac{d \psi}{d \alpha_{H}}=\frac{\lambda}{(r+\lambda+\delta)}\left[b+\frac{c \beta}{(1-\beta)} \psi-\theta_{H}\right] .
$$

Making use of equation (45) the result immediately follows.

The effect of $\theta_{H}$ on market tightness can be understood by considering $\theta_{H}$ as a proxy for the variance of the home productivity shocks on unemployment. As shocks become more dispersed $\left(\theta_{H}\right.$ raises relatively to $\left.\theta_{L}\right)$ the cost of unattachment to the firm rises, with adverse effects on vacancy posting and unemployment. Finally, an increase in $\alpha_{H}$ reduces market tightness, since a higher number of individuals in the high home productivity state implies a larger number of unattached workers. 
A latter result is that, using the non-participation equation (41) in Appendix 9.6 with $q=0$ and $F\left(\theta^{\nu}\right)=1$ (case A), one obtains $n=0$ : everyone participates to the labor market. Instead, in case $\mathrm{B}$, when $F\left(\theta^{\nu}\right)=1-\alpha_{H}$, non-participation is defined by

$$
\frac{n}{1-n}=\frac{\delta}{\delta+p}\left(\frac{\alpha_{H}}{1-\alpha_{H}}-\frac{p}{\delta+\lambda}\right)
$$

Noting that $\partial n / \partial p<0, \partial n / \partial \alpha_{H}>0$ and $\partial n / \partial p<0$, and using the general equilibrium effects of $\psi$ in (16), one obtains the following general equilibrium results:

$$
\frac{d n}{d \lambda}>0 ; \quad \frac{d n}{d \theta_{H}}>0 ; \quad \frac{d n}{d \alpha_{H}}>0 ; \quad \text { if } i_{B}=1 .
$$

They imply that labor force participation falls with the arrival rate and the variance of home productivity shocks, as well as with the proportion of workers in the high home productivity state.

\subsection{Asymmetric information}

Proof of point 1. The total surplus $S(\theta)$ is the sum of the surplus of the firm and of the worker. In $\theta=\widetilde{\theta}^{q}$, the surplus of the worker is zero by definition. So, $S\left(\widetilde{\theta}^{q}\right)=J\left(\widetilde{\theta}^{q}\right)=\frac{y-w}{r+\delta+q\left(\widetilde{\theta}^{q}\right)}$. It is therefore sufficient to show that the wage is lower than $y$. From (20), one has

$$
\frac{y-w}{r+\delta+q\left(\widetilde{\theta}^{q}\right)}=-1 / \frac{\partial q\left(\widetilde{\theta}^{q}\right)}{\partial w}=\lambda f\left(\widetilde{\theta}^{q}\right) \frac{\partial \widetilde{\theta}^{q}}{\partial w} .
$$

From (19), one has that $\frac{\partial \widetilde{\theta}^{q}}{\partial w}=1-\frac{\lambda}{r+\lambda+\delta} F\left(\widetilde{\theta}^{q}\right)>0$ so $y>w$ and $S\left(\widetilde{\theta}^{q}\right)>0$ : there are inefficient destructions.

Proof of point 2. The dual of point 1 : Since the surplus of workers is decreasing with $\theta$ and minimum in $\widetilde{\theta}^{q}, W(\theta)-\operatorname{Max}(U, N(\theta))$ is strictly positive for all $\theta<\widetilde{\theta}^{q}$.

Proof of point 3 . From (46), $S\left(\widetilde{\theta}^{q}\right) \rightarrow 0$ when $\lambda \rightarrow 0$.

\section{References}

[1] Abraham K.G. and Shimer, R. (2001). "Changes in Unemployment Duration and Labor Force Attachment", NBER Working Paper 8501

[2] Abowd, J. and Zellner, A. (1985) "Estimating Gross Labor Force Flows", Journal of Economics and Business Statistics 3, no. 3: 254-83.

[3] Atkinson, A.B. and Micklewright J. (1991). "Unemployment Compensation and Labor Market Transitions: A Critical Review", Journal of Economic Literature, Vol. XXiX, pp. $1679-1727$

[4] Becker G.S.. (1965). " Theory of the Allocation of Time", The Economic Journal, No 299(LXXV), pp493-517 
[5] Benhabib J., Rogerson R., and R. Wright (1991) "Homework in Macroeconomics: Household Production and Aggregate Fluctuations", Journal of Political Economy, 99: 1166-8\%.

[6] Ben Porath D. (1967). "The Production of Human Capital and the Life-Cycle of Earnings", Journal of Political Economy, 75:352

[7] Blanchard O.J. , Diamond P. (1990). "The Cyclical Behavior of the Gross Flows of US Workers", Brooking Papers on Economic Activity 1990:2, p85-155

[8] Boeri, T. and Burda, M. (1999). "Unions in Search Equilibrium", mimeo, HumboldtUniversität zu Berlin.

[9] Burda M., Wyplosz C., 1994, "Gross workers and job flows in Europe", European Economic Review 38(6), p1287-1315

[10] Bowden, R. J. (1980), "On the Existence and Secular Stability of $u-v$ Loci", Economica 47, pp35-50, February

[11] Burdett K., (1979), "Search, leisure and individual labor supply", chapter 8 in Studies in the Economics of Search, Contributions to Economic Analysis, Tinbergen, Jorgenson and Waelbroeck eds., North-Holland

[12] Burdett K. and Mortensen D.T., (1978), "Labor Supply Under Uncertainty", in Research in Labor Economics, Ehrenberg R.G. ed.

[13] Burdett K., Kiefer N., Mortensen D., Neumann G. (1984), "Earnings, Unemployment, and the Allocation of Time Over Time", Review of Economic Studies LI, pp559-578

[14] Daveri, F. and G. Tabellini (2000), "Unemployment, growth and taxation in industrial countries", Economic Policy, forthcoming.

[15] Eisner, R. (1988) "Extended Accounts for National Income and Product" Journal of Economic Literature 1611-84.

[16] Flinn C.J. and Heckman J.J., (1983), "Are Unemployment and Out of the Labor Force Behaviorally Distinct Labor Force States", Journal of Labor Economics, vol.1(1), pp2842

[17] Garibaldi P. and Wasmer E. (2000). "Unattachment to the labor market when search effort $e<1 "$, technical Appendix, mimeo ECARES and Bocconi.

[18] Harsanyi J.C. and Selten, R. (1972). "A Generalized Nash Solution for Two-Person Bargaining Games with Incomplete Information", Management Science, Vol. 18(5), January.

[19] Layard R., Nickell S., and Jackman R., 1991, Unemployment, Oxford, Basil Blackwell 
[20] Juhn C., Murphy, K. and Topel R.H. (1991). "Why Has the Natural Rate of Unemployment Increased over Time?", Brookings Papers on Economic Activity;0(2), 1991, pp. $75-126$

[21] McKenna, C.J. (1987), "Labour Market Participation in Matching Equilibrium", Economica 54, pp325-333

[22] Mortensen, D.T. and Pissarides, C.A. (1994). "Job Creation and Job Destruction in the Theory of Unemployment", Review of Economic Studies, 64, 397-415

[23] Mortensen, D.T. and Pissarides, C.A. (1999). "Job Reallocation, Employment Fluctuations and Unemployment", Handbook of Macroeconomics, vol 3B, Ch. 39

[24] Murphy K. and Topel R. H. (1997). "Unemployment and Nonemployment", American Economic Review; 87(2), May 1997, pp. 295-300

[25] Nickell, S. and Layard, R. (1999) "Labor Market Institutions and Economic Performance", in O. Ashenfelter and D. Card eds. Handbook of Labor Economics, Vol 3c. chapter 46 3029-3084

[26] Rogerson, (1988) "Indivisible Labor, Lotteries and Equilibrium", Journal of Monetary Economics 21: 3-16.

[27] OECD (1999). Benefit Systems and Work Incentives. OECD, Paris.

[28] Pissarides C.A. (1990), Equilibrium Unemployment Theory, Oxford, Basil Blackwell

[29] Pissarides C.A. (1998) "The impact of employment tax cuts on unemployment and wages; the role of unemployment ebenfits and tax structure", European Economic Review, vol. 42, pp. 155-83.

[30] Pissarides, C. (2000), Equilibrium Unemployment Theory, Cambridge (MA.): The MIT Press.

[31] Sattinger M. (1995), "General Equilibrium Effects of Unemployment Compensation with Labor Force Participation", Journal of Labor Economics, vol.13(4), pp623-652

[32] Scarpetta, S. (1996), "Assessing the role of labour market policies and institutional settings on unemployment: a cross country study", OECD Economic Studies 26: 43-98

[33] Seater J.J., (1977), "A Unified Model of Consumption, Labor Supply, and Job Search", Journal of Economic Theory 14, pp349-372

[34] Sorrentino C. (1993). "International comparisons of unemployment indicators ", Monthly Labor Review, March.

[35] Sorrentino C. (1995). "International unemployment indicators, 1983-93", Monthly Labor Review, August. 
[36] Swaim P. and Podgursky, M. (1994), "Female Labor Supply following Displacement: A Split-Population Model of Labor Force Participation and Job Search", Journal of Labor Economics, vol.12(4), pp640-656

[37] Wasmer, E. (1997). "Trends in the Workers Flows and Some Consequences on Unemployment: France 1968-1993", Discussion Paper DELTA 97-14 and Chapter 1 in 'Changes in the Composition of the Labor Force. Consequences for Wages and Employment', unpublished PhD Dissertation, London School of Economics, December 1997.

[38] Weiss, Y. (1986). "The Determination of Life-Cycle Earnings: A survey", Ch. 11 in Handbook of Labor Economics, Vol. 1, O. Ashenfelter and R. Layard, eds. 


\section{IZA Discussion Papers}

\begin{tabular}{|c|c|c|c|c|}
\hline No. & Author(s) & Title & Area & Date \\
\hline 391 & $\begin{array}{l}\text { J. T. Addison } \\
\text { P. Teixeira }\end{array}$ & $\begin{array}{l}\text { Employment Adjustment in Portugal: Evidence } \\
\text { from Aggregate and Firm Data }\end{array}$ & 1 & $11 / 01$ \\
\hline 392 & $\begin{array}{l}\text { P. Tsakloglou } \\
\text { F. Papadopoulos }\end{array}$ & $\begin{array}{l}\text { Identifying Population Groups at High Risk of } \\
\text { Social Exclusion: Evidence from the ECHP }\end{array}$ & 3 & $11 / 01$ \\
\hline 393 & S. M. Fuess, Jr. & Union Bargaining Power: A View from Japan & 2 & $11 / 01$ \\
\hline 394 & $\begin{array}{l}\text { H. Gersbach } \\
\text { A. Schniewind }\end{array}$ & $\begin{array}{l}\text { Awareness of General Equilibrium Effects and } \\
\text { Unemployment }\end{array}$ & 2 & $11 / 01$ \\
\hline 395 & $\begin{array}{l}\text { P. Manzini } \\
\text { C. Ponsatí }\end{array}$ & Stakeholders, Bargaining and Strikes & 6 & $11 / 01$ \\
\hline 396 & $\begin{array}{l}\text { M. A. Shields } \\
\text { S. Wheatley Price }\end{array}$ & $\begin{array}{l}\text { Exploring the Economic and Social } \\
\text { Determinants of Psychological and Psychosocial } \\
\text { Health }\end{array}$ & 5 & $11 / 01$ \\
\hline 397 & $\begin{array}{l}\text { M. Frondel } \\
\text { C. M. Schmidt }\end{array}$ & $\begin{array}{l}\text { Evaluating Environmental Programs: The } \\
\text { Perspective of Modern Evaluation Research }\end{array}$ & 6 & $11 / 01$ \\
\hline 398 & $\begin{array}{l}\text { M. Lindeboom } \\
\text { F. Portrait } \\
\text { G. J. van den Berg }\end{array}$ & $\begin{array}{l}\text { An Econometric Analysis of the Mental-Health } \\
\text { Effects of Major Events in the Life of Elderly } \\
\text { Individuals }\end{array}$ & 5 & $11 / 01$ \\
\hline 399 & $\begin{array}{l}\text { J. W. Albrecht } \\
\text { J. C. van Ours }\end{array}$ & $\begin{array}{l}\text { Using Employer Hiring Behavior to Test the } \\
\text { Educational Signaling Hypothesis }\end{array}$ & 1 & $11 / 01$ \\
\hline 400 & R. Euwals & $\begin{array}{l}\text { The Predictive Value of Subjective Labour } \\
\text { Supply Data: A Dynamic Panel Data Model with } \\
\text { Measurement Error }\end{array}$ & 5 & $11 / 01$ \\
\hline 401 & $\begin{array}{l}\text { J. Boone } \\
\text { P. Fredriksson } \\
\text { B. Holmlund } \\
\text { J. C. van Ours }\end{array}$ & $\begin{array}{l}\text { Optimal Unemployment Insurance with } \\
\text { Monitoring and Sanctions }\end{array}$ & 3 & $11 / 01$ \\
\hline 402 & $\begin{array}{l}\text { O. Ashenfelter } \\
\text { D. Card }\end{array}$ & $\begin{array}{l}\text { Did the Elimination of Mandatory Retirement } \\
\text { Affect Faculty Retirement Flows? }\end{array}$ & 5 & $11 / 01$ \\
\hline 403 & L. Ljungqvist & How Do Layoff Costs Affect Employment? & 1 & $11 / 01$ \\
\hline 404 & $\begin{array}{l}\text { H. Battu } \\
\text { C. R. Belfield } \\
\text { P. J. Sloane }\end{array}$ & Human Capital Spill-Overs Within the Workplace & 1 & $11 / 01$ \\
\hline 405 & L. Locher & Testing for the Option Value of Migration & 3 & $11 / 01$ \\
\hline 406 & $\begin{array}{l}\text { P. Garibaldi } \\
\text { E. Wasmer }\end{array}$ & $\begin{array}{l}\text { Labor Market Flows and Equilibrium Search } \\
\text { Unemployment }\end{array}$ & 1 & $11 / 01$ \\
\hline
\end{tabular}

